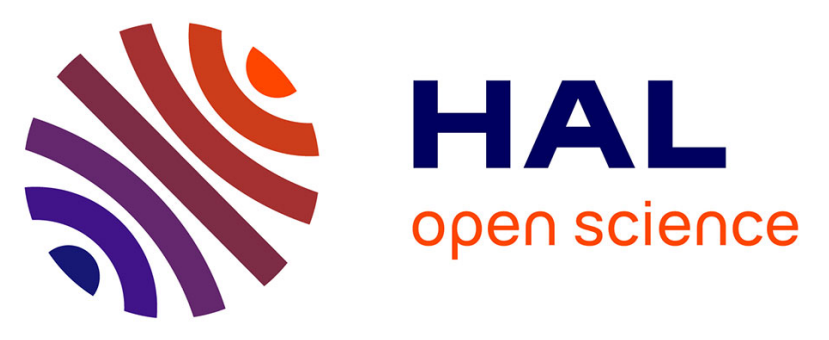

\title{
Synthesis, NMR, Raman, thermal and nonlinear optical properties of dicationic ionic liquids from experimental and theoretical studies
}

\author{
Djebar Hadji, Boumediene Haddad, Silvia Antonia Brandán, Sumit Kumar \\ Panja, Annalisa Paolone, Mokhtar Drai, Didier Villemin, Serge Bresson, \\ Mustapha Rahmouni
}

\section{To cite this version:}

Djebar Hadji, Boumediene Haddad, Silvia Antonia Brandán, Sumit Kumar Panja, Annalisa Paolone, et al.. Synthesis, NMR, Raman, thermal and nonlinear optical properties of dicationic ionic liquids from experimental and theoretical studies. Journal of Molecular Structure, 2020, 1220, pp.128713. 10.1016/j.molstruc.2020.128713 . hal-02880248

\section{HAL Id: hal-02880248}

https://hal-normandie-univ.archives-ouvertes.fr/hal-02880248

Submitted on 24 Jun 2020

HAL is a multi-disciplinary open access archive for the deposit and dissemination of scientific research documents, whether they are published or not. The documents may come from teaching and research institutions in France or abroad, or from public or private research centers.
L'archive ouverte pluridisciplinaire HAL, est destinée au dépôt et à la diffusion de documents scientifiques de niveau recherche, publiés ou non, émanant des établissements d'enseignement et de recherche français ou étrangers, des laboratoires publics ou privés. 


\title{
Synthesis, NMR, Raman, thermal and nonlinear optical properties of dicationic ionic liquids from experimental and theoretical studies
}

\author{
Djebar Hadji ${ }^{\text {a, }}$ Boumediene Haddad ${ }^{\text {a,b, }}$, Silvia Antonia Brandán ${ }^{\text {c, }}$ Sumit Kumar Panja ${ }^{\mathrm{d}}$, Annalisa \\ Paolone ${ }^{\mathrm{e}}$, Mokhtar Drai ${ }^{\mathrm{f}}$, Didier Villemin ${ }^{\mathrm{g}}$, Serge Bresson ${ }^{\mathrm{h}}$, Mustapha Rahmouni ${ }^{\mathrm{i}}$ \\ ${ }^{a}$ Department of chemistry, Dr. Moulay Tahar university of Saida, 20000 Saida, Algeria \\ ${ }^{b}$ Chemistry Laboratory of Synthesis, Properties, and Applications (CLSPA-Saida), 20000 Saida, Algeria \\ ${ }^{c}$ Cátedra de Química General, Instituto de Química Inorgánica, Facultad de Bioquímica. Química y Farmacia, \\ Universidad Nacional de Tucumán, Ayacucho 471, (4000) San Miguel de Tucumán, Tucumán, Argentina. \\ ${ }^{d}$ Department of Chemistry, UkaTarsadia University, Maliba Campus, Gopal Vidyanagar, Bardoli, Mahuba \\ Road, Surat-394350, Gujrat, India. \\ ${ }^{e}$ CNR-ISC, U.O.S. La Sapienza, Piazzale A. Moro 5, 00185 Roma, Italy \\ ${ }^{f}$ UniversitéDjillaliLiabes, BP 89, 22000 Sidi-Bel-Abbes, Algeria \\ ${ }^{g}$ LCMT, ENSICAEN, UMR 6507 CNRS, University of Caen, 6 bdMlJuin, 14050 Caen, France \\ ${ }^{h}$ Laboratoire de Physique des Systèmes Complexes, Université Picardie Jules Verne, 33 rue St Leu, 80039 \\ Amiens cedex, France. \\ 'Synthesis and Catalysis Laboratory LSCT, Tiaret University, Tiaret, Algeria
}

\begin{abstract}
In this work, two new di-cationic imidazolium based ILs containing chloride, (bisImCl) and hexafluorophosphate anion (bisImPF 6 ) have been synthesized and characterized by using FTRaman and ${ }^{1} \mathrm{H}$ - and ${ }^{13} \mathrm{C}$-NMR spectroscopies. The p-xylyl group acts a spacer group between two imidazolium cations. B3LYP/6-311++G** calculations have optimized the structure of bisIm cation with both anion $\mathrm{Cl}$ in monodentate coordinations while in bisImPF 6 only a $\mathrm{PF}_{6}$ group presents monodentate coordination. AIM calculations at the same level of theory have evidenced a higher number of interactions in bisImPF 6 , as compared with bisImCl. The effect of anions on thermal properties has been investigated. The thermal behavior confirmed that bisImCl and bisImPF 6 have shown good thermal stability. The complete assignments for cation, bisImCl and bisImPF 6 are here reported together with a set of harmonic scaled force constants calculated for cation and bisImCl. Intermolecular and cation-anion interactions have been investigated by NMR spectroscopy. Further, polarizability $(\alpha)$ and the static first hyperpolarizabilities $(\beta)$ of these ILs are calculated by DFT functionals in order to understand nonlinear optical (NLO) properties. It is also observed an inversed correlation between the predicted $\beta$ value and the HOMO-LUMO energy difference $(\Delta \varepsilon)$ from two state models. The high gap value observed for bisImPF $\mathrm{F}_{6}$ justify its low reactivity, as supported by high number interactions predicted for this ionic liquid.
\end{abstract}

Keywords: Dicationic Ionic liquids; Vibrational spectra; Coordination; NMR; Thermal study; Nonlinear optical properties.

* Corresponding author. Haddad boumediene

E-mail : E-mail: haddadboumediene@yahoo.com 


\section{Introduction}

Ionic liquids (ILs) are fascinating ionic materials that have attracted considerable attention due to their unique properties, which can be tailored for specific applications ranging from chemical synthesis and separation processes to media for electrochemical devices [1-3]. Imidazolium-based ILs are very popular due to their chemical and thermal stability, wellestablished structural characterization, low viscosity, and their widespread potential applications [4,5]. For example, varying the substituents of the imidazolium ring drastically changes the physical properties of these ILs [6]. The attractive and potentially tunable properties of these fascinating materials make them not just replacements for conventional solvents, but open up opportunities to use them as new platforms for advanced multipurpose materials [7,8], for example by combining them with nanostructured materials [9]. Very recently, it has been pointed out that the chemical and physical properties of imidazoliumbased ILs are determined by the interactions between the counter-ions. In addition, the ability to control and varying the substitutes of these ionic materials drastically changes the physical properties [10-12]. Further, studying DILs is another highly active area of research that aims at understanding the structure-property relationships. Despite the wealth of papers on DILs and their applications $[13,14]$, there are a few experimental and computational studies on DILs to understand their structure-property relationships and NLO properties [15-17]. Studies of NLO properties of DILs are very important due to their potential applications in photonics and telecommunication, because each combination of anion and cation gives different value of NLO properties depending on the weak interaction of coupled cations with anions [16].

One of the major positive points in ionic compounds in the NLO behavior is the possibility of alignment of ionic chromophores, which can be controlled by changing the counter ion [17]. Moreover, such behavior depends on various parameters, such as the dispersion forces, the magnitude of interaction energy, and the hydrogen bonding interactions, the orientation and the predominant long-range coulombic forces [18]. From an experimental point of view, it is known, that the Z-scan technique is used to determine the NLO properties such as the nonlinear absorption and the index nonlinear refraction, due to its unpretentiousness [19]. It is also reported that change of the refractive index can induce variations of the heat conduction process, which is directly related to the nonlocal character of the optical nonlinearity [20]. Several theoretical studies [21-23] showed that large second-order NLO responses in ILs could increase the response time of electro-optic switching elements for optical information 
processing and telecommunications. In order to determine the relation between NLO properties of ILs, Águila et al. [15] indicated that these ILs are good candidates for the development of NLO devices. Ostroverkhova et al. [24] showed that ILs can be used in materials for optical holographic recording, in catalysis [25] and for electrical-controlled memory systems [26]. It is possible to increase the NLO response of ILs, with the increase of the $\pi$-conjugation group and introduce strong anion. In our DILs, the opportunity to change the anion $\left(\mathrm{Cl}^{-}\right.$and $\left.\mathrm{PF}_{6}^{-}\right)$play a crucial role to increase the NLO response. To provide a more detailed understanding of the effect of chloride $\left(\mathrm{Cl}^{-}\right)$and hexafluorophosphate $\left(\mathrm{PF}_{6}^{-}\right)$anion in these two DILs (bisImCl and bisImPF 6 ) based with xylene spacer group on physical and electronic properties, TGA, NMR and Raman spectroscopic techniques are employed to characterize those two DILs. In addition, the NLO properties of two DILs (bisImCl and bisImPF${ }_{6}$ ) were analyzed by calculating their polarizability, anisotropy of polarizability and first hyperpolarizability by performing DFT calculation using different functionals.

\section{Materials and Methods}

\subsection{Synthesis and chemicals characterization}

The reagents used in this study, 1-methyl-1H-imidazole (>99\%), $\alpha, \alpha^{\prime}$-dichloro-p-xylene (98\%), diethyl ether and N,N-dimethylformamide, potassium hexafluorophosphate $(99.5 \%)$ were purchased from Fluka and used as received. Deionized water was obtained with a Millipore ion-exchange resin deionizer.

\subsubsection{Synthetic procedure of DILs:}

BisImCl DIL is synthesized in the same ways as reported in our previous work [27]. As mentioned in the Scheme 1, the bisImCl DIL is dissolved in water and then an aqueous solution of $\mathrm{KPF}_{6}$ is slowly added to the previous solution containing bisImCl DIL with constant stirring for $3 \mathrm{hrs}$ at room temperature. After that, a white precipitate appeared from the resultant solution. The Dichloromethane (DCM) is added to the solution to dissolve the white precipitate. After that, DCM solution is washed with cold water at least 2-3 times. The presence of halide is checked by $\mathrm{AgNO}_{3}$. Subsequently, DCM is dried with anhydrous $\mathrm{MgSO}_{4}$. The DCM solution is further treated with activated charcoal to remove coloured impurities and then passed through a column containing alumina and celite. In order to remove volatile components and water, DIL are dried under constant stirring at a temperature of $298 \mathrm{~K}$ for $24 \mathrm{~h}$ at a reduced pressure of $2 \mathrm{~Pa}$. Finally, by means of a Metrohm 831, Karl Fischer titration is carried out to confirm the water content below $150 \mathrm{ppm}$. 


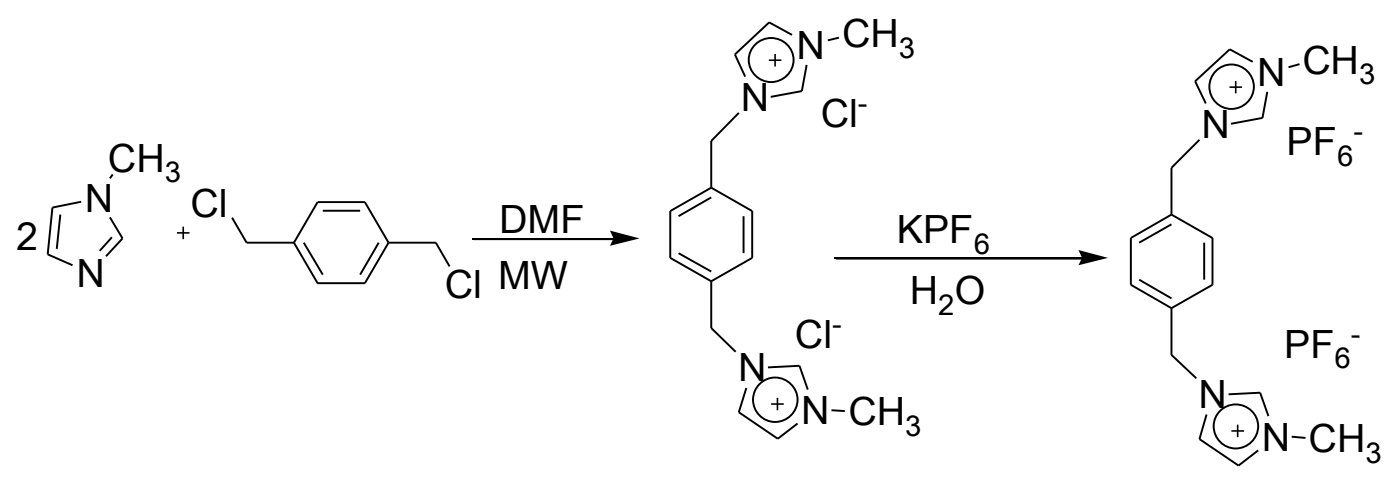

Scheme 1.General synthesis of bisImCl and bisImPF 6 (MW = microwave $)$

After drying, the samples were handled under argon atmosphere. The yield of obtained bisImPF 6 was $76 \%$. The structures of obtained DILs are confirmed by using ${ }^{1} \mathrm{H},{ }^{13} \mathrm{C},{ }^{19} \mathrm{~F},{ }^{31} \mathrm{P}$ NMR and FTIR spectroscopy, in order to check the occurrence of the expected chemical reactions and confirm the absence of any impurities. The NMR analysis of both DILs is described in Section 3.3. Also, the ${ }^{13} \mathrm{C},{ }^{19} \mathrm{~F},{ }^{31} \mathrm{P}$ - NMR spectroscopic data are given in Supporting Information (Figure S1-S2).

\subsection{Instrumentation}

\subsubsection{NMR Spectroscopy:}

${ }^{1} \mathrm{H}-\mathrm{NMR}$ (500 MHz), ${ }^{13} \mathrm{C}-\mathrm{NMR}(125.75 \mathrm{MHz}),{ }^{19} \mathrm{~F}-\mathrm{NMR}(470.62 \mathrm{MHz})$ and ${ }^{31} \mathrm{P}-\mathrm{NMR}$ (202.47 MHz) spectra were recorded on a Bruker DRX $500 \mathrm{MHz}$ spectrometer. Spectra were recorded in dimethylsulfoxide (DMSO- $d_{6}$ ), using the DMSO residual peak as the ${ }^{1} \mathrm{H}$ internal reference $\left(\delta=2.5\right.$ and 3.3), and the central peak of DMSO- $d_{6}$ at $\delta=39.5$ for the ${ }^{13} \mathrm{C}$ reference. Chemical shifts $(\delta)$ are given in ppm and referred to the internal solvent signal, namely TMS, $\mathrm{H}_{3} \mathrm{PO}_{4}$ and $\mathrm{CFCl}_{3}$, respectively.

\section{3,3'-dimethyl-1,1'-(1,4-phenylenedimethylene)-bis(1H-imidazolium) dichloride}

${ }^{1}$ H-NMR (bisImCl) : $\left(\mathrm{DMSO}-d_{6}\right): \delta_{\mathrm{H}}(\mathrm{ppm}) 9.48(\mathrm{~s}, \mathrm{NCHN}, 2 \mathrm{H}), 7.85$ (s, NCHC, 2H), 7.74 (s, NCHC, 2H), 7.51 (s, $\left.-\mathrm{C}_{6} \mathrm{H}_{4-}, 4 \mathrm{H}\right), 5.47$ (s, $\left.-\mathrm{CH}_{2-}, 4 \mathrm{H}\right), 3.86\left(\mathrm{~s}, 2 \times \mathrm{CH}_{3}, 6 \mathrm{H}\right) ;{ }^{13} \mathbf{C}-\mathbf{N M R}$ $\left(\mathrm{DMSO}-\mathrm{d}_{6}\right):(\delta \mathrm{ppm}) 36.34,51.67,122.66,124.62,129.40,135.73,137.22$.

FTIR (bisImCl) : $\left(\tilde{v} / \mathrm{cm}^{-1}\right): 3032\left[v(=\mathrm{C}-\mathrm{H})_{\mathrm{Arom}}\right], 2874[v(\mathrm{C}-\mathrm{H})], 1560[v(\mathrm{C}=\mathrm{C})], 1442[\delta(\mathrm{C}-$ $\mathrm{H})], 1081[v(\mathrm{C}-\mathrm{N})], 742[v(\mathrm{C}-\mathrm{H})]$.

\section{3,3'-dimethyl-1,1'-(1,4-phenylenedimethylene)-bis(1Himidazolium) bis}

\section{(hexafluorophosphate)}

${ }^{1}$ H-NMR (bisImPF $)$ : $\left(\right.$ DMSO- $\left.d_{6}\right): \delta_{\mathrm{H}}(\mathrm{ppm}) 9.23(\mathrm{~s}, \mathrm{NCHN}, 2 \mathrm{H}), 7.74(\mathrm{~s}, \mathrm{NCHC}, 2 \mathrm{H})$, 7.67 (s, NCHC, 2H), 7.47 (s, $\left.-\mathrm{C}_{6} \mathrm{H}_{4-}, 4 \mathrm{H}\right), 5.42\left(\mathrm{~s},-\mathrm{CH}_{2}-, 4 \mathrm{H}\right), 3.84\left(\mathrm{~s}, 2 \times \mathrm{CH}_{3}, 6 \mathrm{H}\right){ }^{\mathbf{1 3}} \mathbf{C}_{-}$ NMR (DMSO- $\left.\mathrm{d}_{6}\right):(\delta \mathrm{ppm}) 36.25,51.78,122.68,124.46,129.42,135.64,136.95 ;{ }^{19}$ F-NMR 
$\left(\mathrm{DMSO}-\mathrm{d}_{6}\right): \delta_{\mathrm{F}}(\mathrm{ppm})-70.7,-69.2\left(\mathrm{~d}, J_{\mathrm{FP}}=711.25 \mathrm{~Hz}\right) ;{ }^{31} \mathbf{P}-\mathbf{N M R}\left(\mathrm{DMSO}-\mathrm{d}_{6}\right): \delta_{\mathrm{P}}(\mathrm{ppm})-$ 144.24, (septet, $J_{\mathrm{PF}}=711.58 \mathrm{~Hz}$ ).

FTIR (bisImPF 6$)\left(v / \mathrm{cm}^{-1}\right): 3174 / 3137\left[v(=\mathrm{C}-\mathrm{H})_{\mathrm{Arom}}\right], 2942[v \quad(\mathrm{C}-\mathrm{H})], 1571[(\mathrm{C}=\mathrm{N})], 1516$ $(\mathrm{C}-\mathrm{C}), 1451[\delta(\mathrm{C}-\mathrm{H})], 1081[v(\mathrm{C}-\mathrm{N})], 822[v(\mathrm{P}-\mathrm{F})], 612[v(\mathrm{C}-\mathrm{H})]$.

\subsubsection{FT-IR and FT-Raman spectroscopy}

Preliminary IR spectra were recorded on a FT-IR Perkin-Elmer Spectrum BX spectrophotometer with a resolution of $4 \mathrm{~cm}^{-1}$ in the range $4000-650 \mathrm{~cm}^{-1}$ in order to check the occurrence of the expected chemical reactions and the production of the DILs.

The FT-RAMAN spectra were acquired on a Vertex 70-RAM II Bruker FT-Raman spectrometer. This instrument is equipped with a Nd:YAG laser (yttrium aluminium garnet crystal doped with triply ionized neodymium) with a wavelength of $1064 \mathrm{~nm}$ and a maximum power of $1.5 \mathrm{~W}$. The measurement accessory is pre-aligned: only the Z-axis of the scattered light is adjusted to set the sample in the appropriate position regarding the local measurement point. The RAM II spectrometer is equipped with a liquid nitrogen cooled Ge detector. FTRaman spectra [45-4000 $\mathrm{cm}^{-1}$ ] were collected with $1 \mathrm{~cm}^{-1}$ resolution by co-adding 128 scans for each spectrum at room temperature. The OPUS 6.0 software was used for the spectral acquisition, manipulation and transformation.

\subsubsection{Thermal analysis}

Concomitant thermogravimetric analysis (TGA) and differential thermal analysis (DTA) measurements were performed by means of a Setaram Setsys Evolution 1200 TG System. For each sample, a mass of $\sim 15 \mathrm{mg}$ was used; the heating rate temperature was fixed at $5{ }^{\circ} \mathrm{C} / \mathrm{min}$ and the measurements were performed under a dynamical helium flux of $60 \mathrm{ml} / \mathrm{min}$.

\subsubsection{Quantum Chemical Calculation}

The DFT/B3LYP level having 6-311++G(d,p) basis set were employed to optimize the geometries of both DILs in gas phase. This level was also used for predicting the interactions between cation and anion in DILs by using the AIM 2000 program at the same level of theory $[28,29]$. Then, the scaled quantum mechanical force field (SQMFF) approach and the Molvib program were employed in the vibrational analysis together with the normal internal coordinates [30-32]. In the assignments process only those potential energy distribution (PED) contributions $\geq 10 \%$ have been considered. The mean polarizability $\langle\alpha\rangle$, anisotropy polarizability $|\alpha|$, the hyper-Rayleigh scattering (HRS) first hyperpolarizability $\beta_{\mathrm{HRS}}(-2 \omega ; \omega, \omega)$ and the depolarization ratio (DR) are reported and interpreted for these DILs. These calculations are performed using selected exchange-correlation (XC) DFT 
functionals, B3LYP and CAM-B3LYP at the 6-311+G(d) and aug-cc-pVDZ basis sets. The Gaussian 09 suite of programs [33] was used for all calculations. The GaussView 5.1 program [34] was used to visualize the structures and the frontier molecular orbitals HOMOs and LUMOs. The dispersion effects were taken into account using the CAM-B3LYP functional with 6-311++G (d,p) basis set [35]. The Moldraw program was used to visualize the cationsanions interactions in both DILs and to calculate the volumes of cations and both DILs [36].

\section{Results and discussion}

\subsection{Optimized structures of DILs}

Optimized structures of BisIm cation, and ionic liquids BisImCl and $\mathrm{BisImPF}_{6}$ in gas phase by using B3LYP/6-311++G** calculations can be easily seen in Figure 1 while in Figure 2 are shown the intermolecular cations-anions contacts by using the same level of theory with the Moldraw program [36]. R1 and R2 are designed to the five member's rings while R3 is named to six members ring. In Bis $\mathrm{ImCl}$ it is possible to observe monodentate ccordinations of $\mathrm{Cl}$ atoms with $\mathrm{C}-\mathrm{H}$ bonds of imidazolium groups while in bisImPF 6 only a PF6 group is in monodentate coordination with the $\mathrm{C}-\mathrm{H}$ bond corresponding to cation. This fact implies that the $\mathrm{Cl}$ atoms have higher facility to interaction with the $\mathrm{H}$ atoms of $\mathrm{C}-\mathrm{H}$ bonds than the $\mathrm{PF}_{6}$.

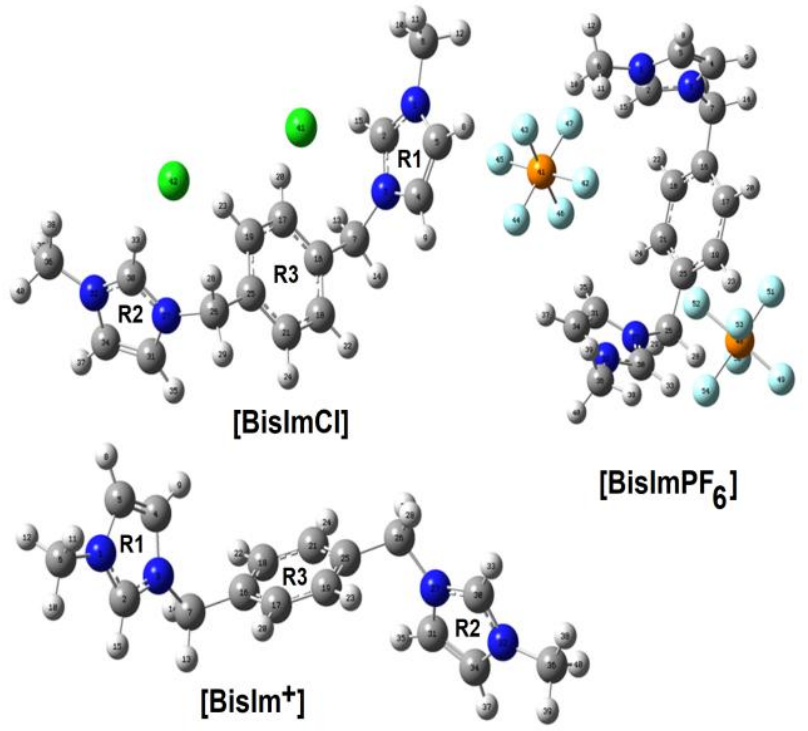

Figure 1. Optimized structures of bisIm cation, and ionic liquids bisImCl and bisImPF 6 in gas phase by using B3LYP/6-311++G** calculations.

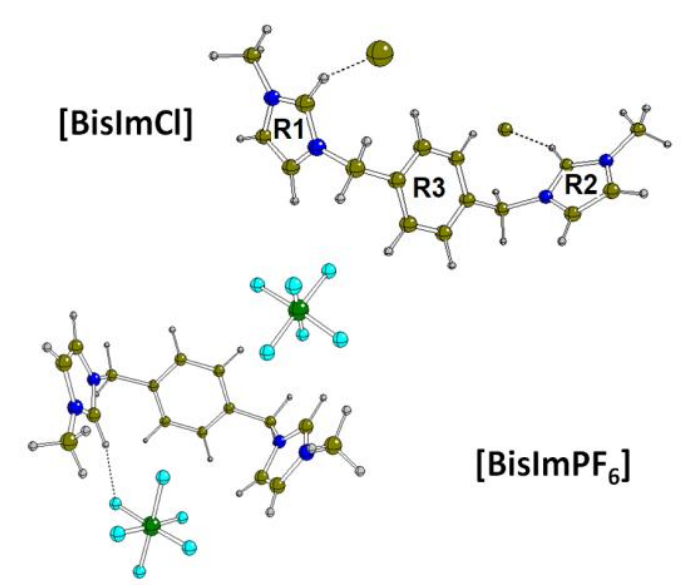

Figure 2. Optimized structures of ionic liquids bisImCl and bisImPF 6 in gas phase showing the intermolecular cations-anions contacts by using B3LYP/6-311++G** calculations. 
In Table 1 are summarized calculated and corrected by ZPVE total energies, dipole moments and volumes of cation and ionic liquids bisImCl and bisImPF 6 in gas phase by using B3LYP/6-311++G** calculations. The ionic liquid bisImCl presents the higher dipole moment value probably due to great size of $\mathrm{Cl}$ atoms while the higher volume is observed for bisImPF 6 . Note that the energies values have lower values when they are corrected by ZPVE, as also was observed in the ionic liquid 1-Ethyl-3-methylimidazolium hexafluorophosphate [37].

Table 1. Calculated and corrected by ZPVE total energies $(E)$, dipole moments $(\mu)$ and volumes (V) of 3,3'-dimethyl-1,1'-(1,4-phenylenedimethylene)-bis(1H-imidazolium) cation $\left[\right.$ bis $\left.^{+}{ }^{+}\right]$and ionic liquids 3,3'-dimethyl-1,1'-(1,4-phenylenedimethylene)-bis $(1 \mathrm{H}-$ imidazolium) dichloride [bisImCl] and 3,3'-dimethyl-1,1'-(1,4-phenylenedimethylene)bis(1Himidazolium) bis(hexafluorophosphate) [bisImPF 6 by using B3LYP/6-311++G** calculations.

\begin{tabular}{ccccc}
\hline Species & E (Hartrees) & ZPVE (Hartrees) & $\mu(\mathrm{D})$ & $\mathrm{V}\left(\AA^{3}\right)$ \\
\hline$\left[\right.$ bisIm $\left.^{+}\right]$ & -840.4608 & -840.1189 & 2.78 & 305.3 \\
{$[$ bisImCl $]$} & -1761.4232 & -1761.0823 & 10.25 & 359.7 \\
{$\left[\right.$ bisImPF $\left._{6}\right]$} & -2722.5778 & -2722.1967 & 8.91 & 470.0 \\
\hline
\end{tabular}

Zero point vibrational energy (ZPVE)

\subsection{AIM studies}

The Bader's theory is a tool very attractive to know the characteristics of different interactions by means of the topological properties by using the AIM 2000 program and the molecular graphics obtained accordingly [28,29]. For both bisImCl and bisImPF 6 the corresponding molecular graphics in gas phase by using B3LYP/6-311++G** calculations are given in Figures 3 and 4, respectively. 


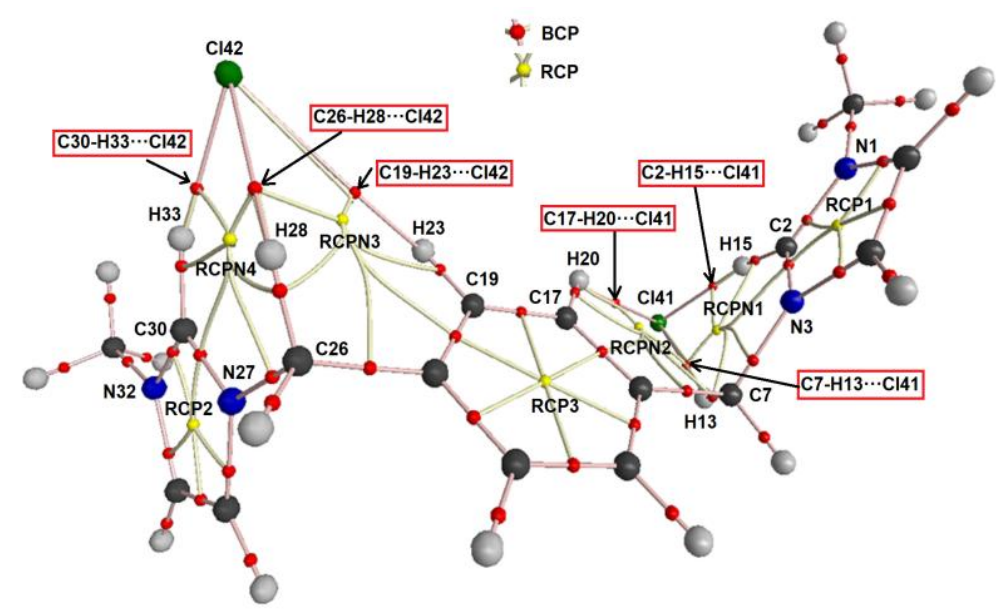

Figure 3. Molecular graphic of bisImCl in gas phase showing the intermolecular interactions by using B3LYP/6-311++G** calculations.

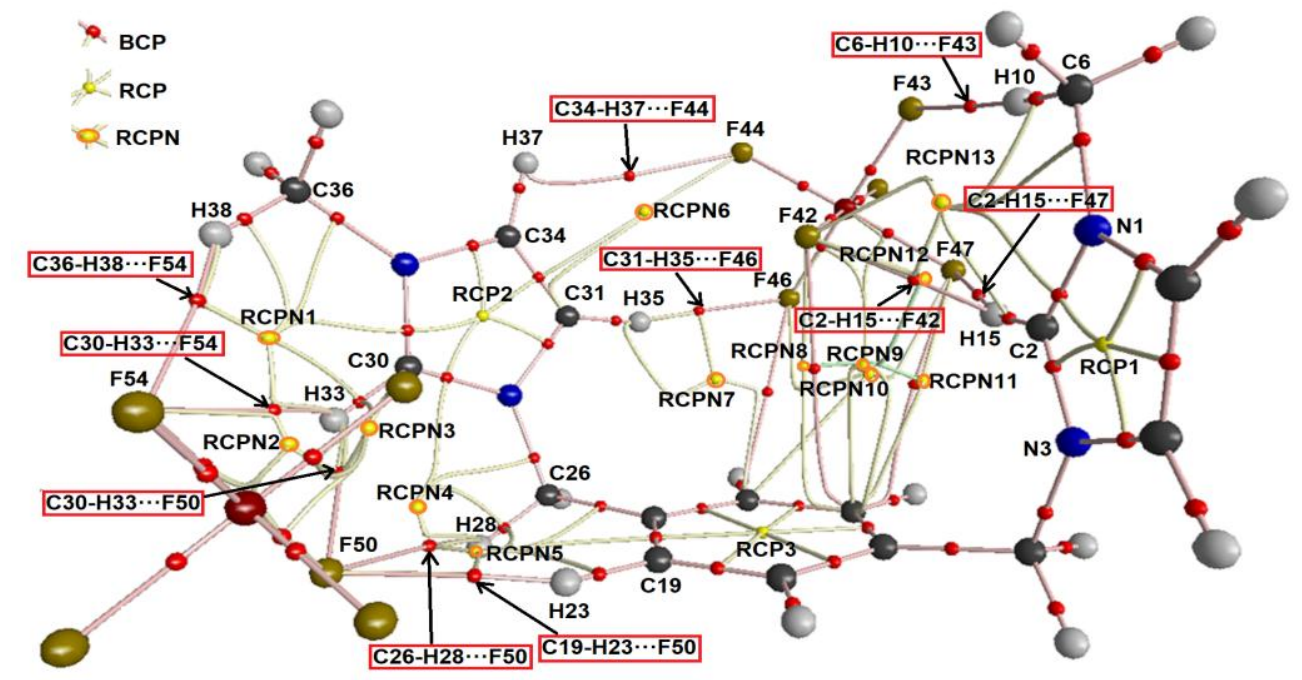

Figure 4. Molecular graphic of bisImPF 6 in gas phase showing the intermolecular interactions by using B3LYP/6-311++G** calculations.

Here, the topological properties are not presented due to the numerous interactions predicted for bisImPF 6 . The ionic or highly polar covalent interactions with $\lambda 1 / \lambda 3<1$ and $\nabla^{2} \rho(r)>0$ (closed-shell interaction) are identified in the two figures (3-4) with red rectangles. RCPs of yellow colours are designed to the ring critical points while the BCPs of red colours are the bond critical points. The BCPs give rise to new critical points of rings called RCPN, where in bisImCl are observed four while in bisImPF 6 the number increase to thirteen. Six $\mathrm{H}$ bonds interactions are predicted in bisImCl which are: $\mathrm{C} 2-\mathrm{H} 15 \cdots \mathrm{Cl} 41, \mathrm{C} 7-\mathrm{H} 13 \cdots \mathrm{Cl} 41, \mathrm{C} 17-$ $\mathrm{H} 20 \cdots \mathrm{Cl} 41, \mathrm{C} 19-\mathrm{H} 23 \cdots \mathrm{Cl} 42, \mathrm{C} 26-\mathrm{H} 28 \cdots \mathrm{Cl} 42$ and $\mathrm{C} 30-\mathrm{H} 33 \cdots \mathrm{Cl} 42$. The RCPs of the three rings are called $\mathrm{RCP} 1, \mathrm{RCP} 2$ and $\mathrm{RCP} 3$. Ten interactions are predicted for bisImPF 6 which 


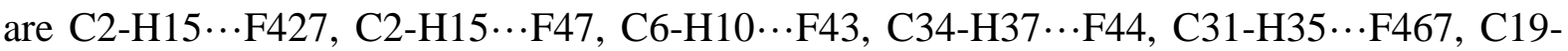
$\mathrm{H} 23 \cdots \mathrm{F} 50, \mathrm{C} 26-\mathrm{H} 28 \cdots \mathrm{F} 50, \mathrm{C} 30-\mathrm{H} 33 \cdots \mathrm{F} 50, \mathrm{C} 30-\mathrm{H} 33 \cdots \mathrm{F} 54$ and $\mathrm{C} 36-\mathrm{H} 38 \cdots \mathrm{F} 54$. In this ionic liquid there are thirteen new RCPs. Hence, these studies suggest a high stability for bisImPF${ }_{6}$, as compared with bisImCl due to high number of $\mathrm{H}$ bonds interactions.

\subsection{NMR Spectroscopy}

The above studies have allowed observing that probably the different interactions in DILs and the nature of anion would significantly affect the ${ }^{1} \mathrm{H}-\mathrm{NMR}$ chemical shifts when these ILs have strongly coordinating anions. For these reasons, the NMR spectroscopy has been widely used to elucidate the structure and cation-anion interactions in ILs [38-44].

For investigating intermolecular interactions and effect of anion on ${ }^{1} \mathrm{H}-\mathrm{NMR}$ chemical shifts, bisImCl and bisImPF 6 DILs are chosen and presented in figure 5. From ${ }^{1} \mathrm{H}-\mathrm{NMR}$ chemical shifts, six signals are obtained for each DILs. In the bisImCl, the characteristic peak for $\mathrm{N}$ methyl protons $\left(\mathrm{CH}_{3}\right)$ appeared as a singlet at $\delta_{\mathrm{H}}=3.86 \mathrm{ppm}$, the resonance of the methylene protons $\left(-\mathrm{CH}_{2}-\right)$ is observed as a singlet at $\delta_{\mathrm{H}}=5.47 \mathrm{ppm}$. While, the aromatic phenyl groups $\left(-\mathrm{C}_{6} \mathrm{H}_{4}-\right)$ resonates in the downfield region at $\delta_{\mathrm{H}}=7.51 \mathrm{ppm}$, for the proton of imidazolium ring: $\mathrm{C}_{4}-\mathrm{Hand} \mathrm{C}_{5}-\mathrm{H}$ were displayed at $\delta_{\mathrm{H}}=7.74$ and $7.85 \mathrm{ppm}$, respectively. The chemical shift $\mathrm{C}_{2}$-Hwas observed at $9.48 \mathrm{ppm}$ for bisImCl and $9.23 \mathrm{ppm}$ for bisImPF 6 DIL. As shown in figure 5, smaller differences in proton peaks are indeed within $0.02,0.03,0.04 \mathrm{ppm}$ in $\delta_{\mathrm{H}}\left(\mathrm{CH}_{3}\right), \delta_{\mathrm{H}}\left(-\mathrm{CH}_{2}-\right)$ and $\delta_{\mathrm{H}}\left(-\mathrm{C}_{6} \mathrm{H}_{4}-\right)$ respectively, between bisImCl and bisImPF 6 . The major difference observed with the protons in the imidazolium cation $\mathrm{C}_{4}-\mathrm{Hand} \mathrm{C}_{5}-\mathrm{H}$, the peaks being shifted by $0.07,0.11 \mathrm{ppm}$. The $\mathrm{C}_{2}-\mathrm{H}$ proton shows that the difference in chemical shift is $0.25 \mathrm{ppm}$ from bisImCl to bisImPF 6 .

The ${ }^{1} \mathrm{H}-\mathrm{NMR}$ spectra show more significant upfield shifts for bisImPF $\mathrm{P}_{6}$ compared to bisImCl. Moreover, these shifts are stronger for the aromatic protons $\left(\mathrm{C}_{2}-\mathrm{H}, \mathrm{C}_{4}-\mathrm{H} / \mathrm{C}_{5}-\mathrm{H}\right)$ than for the methylene and phenyl $\left(\left(\mathrm{CH}_{3}\right),\left(-\mathrm{CH}_{2}-\right),\left(-\mathrm{C}_{6} \mathrm{H}_{4}-\right)\right)$. The ${ }^{1} \mathrm{H}-\mathrm{NMR}$ shift is largest for the $\mathrm{C}_{2}-\mathrm{H}$ proton (from $9.48 \mathrm{ppm}$ for bisImCl to $8.23 \mathrm{ppm}$ for bisImPF $\mathrm{F}_{6}$ and slightly smaller for the $\mathrm{C}_{4}$ $\mathrm{H} / \mathrm{C}_{5}-\mathrm{H}$ signals (from7.85/7.74 ppm for bis $\mathrm{ImCl}$ to $7.74 / 7.67 \mathrm{ppm}$ for bis $\mathrm{ImPF}_{6}$ ). Headley et al.[39] have compared the ${ }^{1} \mathrm{H}$ and ${ }^{13} \mathrm{C}-\mathrm{NMR}$ spectra of 1-n-butyl-3methylimidazoliumtetrafluoroborate $\left(\mathrm{BMI}^{+} \mathrm{BF}_{4}^{-}\right)$with that of 1-n-butyl-3methylimidazoliumhexafluorophosphate $\left(\mathrm{BMI}^{+} \mathrm{PF}_{6}^{-}\right)$and found that the chemical shift of the $\mathrm{H}_{2}$ proton in $\left(\mathrm{BMI}^{+} \mathrm{BF}_{4}^{-}\right)$moved significantly downfield compared to that of and $\left(\mathrm{BMI}^{+} \mathrm{PF}_{6}^{-}\right)$, suggesting that the anion plays a major role in determining the $\mathrm{C}_{2}-\mathrm{H}$ chemical shift. 
In our case, the finding clearly indicates that the chloride anion has the ability to form a tighter interaction with the hydrogen atoms $\mathrm{C}_{2}-\mathrm{H}$ position of the imidazolium cation than $\mathrm{PF}_{6}$, as observed in figure 2. On the other hand, the charge transfer between cations and anions plays a crucial role in the interionic interactions. Our results agree very well with previously published works $[45,46]$. It is also reported that the charge transfer in the case of the chloride anion is considerably higher than that of the hexafluorophosphate anion [47].

Chemical shifting towards upfield region values from chloride anion to $\mathrm{PF}_{6}$, can be explained on basis of basicity nature and coordinating behaviour of anion. It is considered that $\mathrm{PF}_{6}$ anion acts as one of the least basic anions, larger and weaker coordinating anion, supported by previous work $[48,49]$.

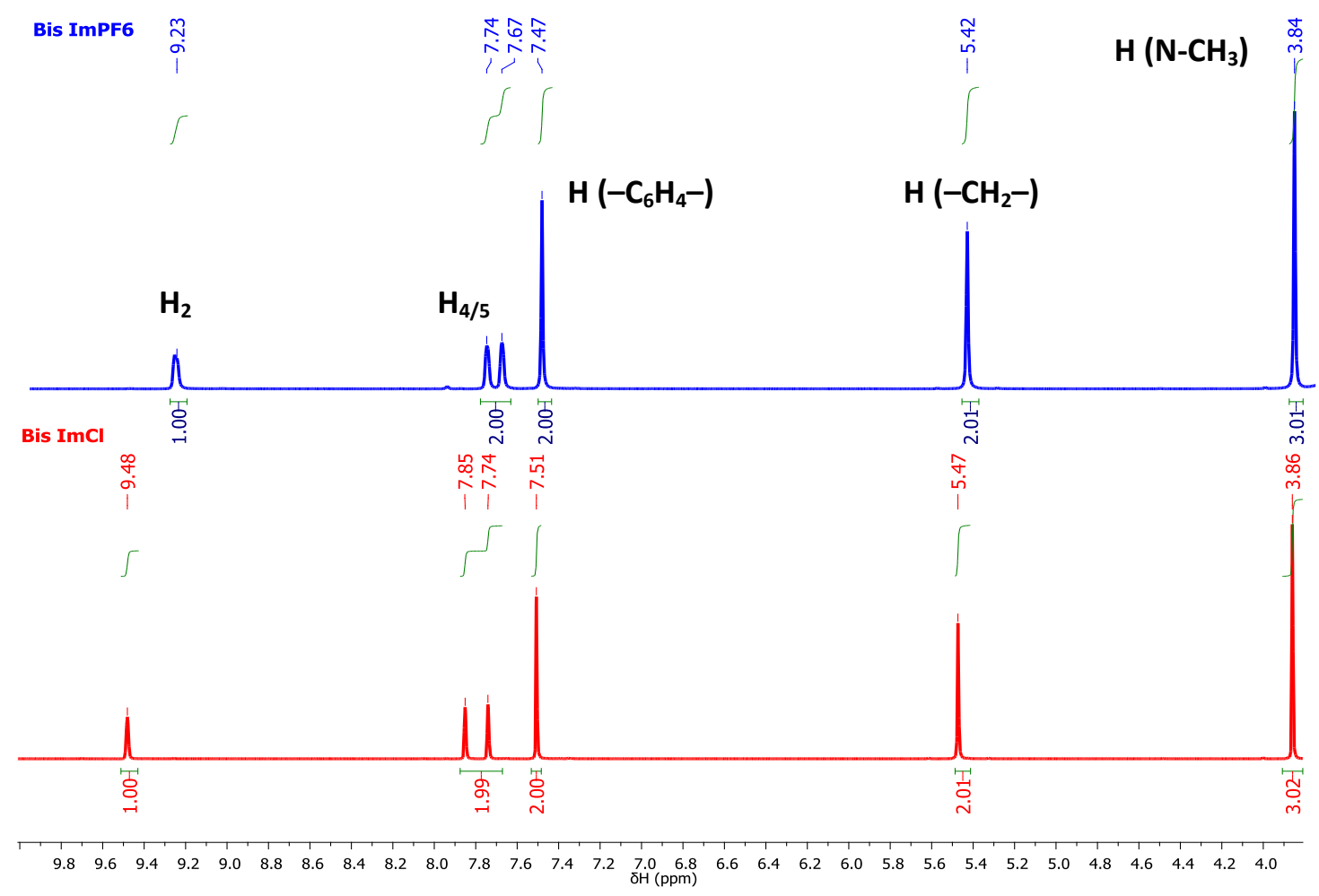

Figure 5. ${ }^{1} \mathrm{H}-\mathrm{NMR}$ spectra of bisImCl and bisImPF 6 in DMSO- $d_{6}$.

The experimental ${ }^{13} \mathrm{C}-\mathrm{NMR}$ spectra of bisImCl and bisImPF $\mathrm{F}_{6} \mathrm{in} \mathrm{DMSO}-d_{6}$ are presented in ESI-FigureS1. In ${ }^{13} \mathrm{C}-\mathrm{NMR}$ spectrum, seven signals were observed for both DILs. For the bisImCl, DIL, $\mathrm{C}_{4}$ and $\mathrm{C}_{5}$ carbons of imidazolium give signals and appeared at $\delta_{\mathrm{c}}=122.5,124.4$ ppm, respectively; while, the chemical shift of the $C_{2}$ signal is located at $137.2 \mathrm{ppm}$. In the other side, the aromatic phenyl carbons $\left(-\mathrm{C}_{\text {aro }}-\right)$ are highly electronegative and decrease the electron density at the ring carbon. Therefore, they show very high chemical shifts values observed at $129.40,135.8 \mathrm{ppm}$. The peak for methylene $\left(-\mathrm{C}_{\text {methylene }}-\right)$ carbonis appeared at 
$51.5 \mathrm{ppm}$ and the carbon of $\mathrm{N}$-methyl $\left(\mathrm{C}_{\text {methyl }}\right)$ has peak at $36.2 \mathrm{ppm}$. Similarly, the ${ }^{13} \mathrm{C}-\mathrm{NMR}$ signals of bisImPF 6 are approximately constant compared within the whole carbon groups in bisImCl and changes are very small. Both ${ }^{1} \mathrm{H}$ and ${ }^{13} \mathrm{C}-\mathrm{NMR}$ results are in good agreement with those obtained from same analogues DILs with bromide anion published by Ibrahim et al. [45]. Finally, the ${ }^{19} \mathrm{~F}$ of bisImPF 6 showed two signals at -70.8 and $-69.3 \mathrm{ppm}$ from coupling between six equivalent fluorine nuclei and phosphorus nucleus with coupling constant $711 \mathrm{~Hz}$ and septet (Figure.S2), both signals are very similar to those reported in our investigated meta -xylyl linked ionic liquids [49]. In case of ${ }^{31} \mathrm{P}-\mathrm{NMR}$ spectrum, signal of $\mathrm{P}$ atom is appeared $-144.3 \mathrm{ppm}$ with coupling constant $\left(\mathrm{J}_{\mathrm{P}-\mathrm{F}}\right) 711.13 \mathrm{~Hz}$ [49]. Again, these values were found to be in good agreement with published data for related compounds [37, 54-55].

\subsection{Vibrational study}

B3LYP/6-311++G** calculations have optimized the structures of two DILs (bisImCl and bis $\mathrm{ImPF}_{6}$ ) and the corresponding to cation in gas phase with $C_{1}$ symmetries, for which, all modes are IR and Raman active. The number of vibrations modes expected for cation, bisImCl and bisImPF 6 are respectively 114, 120 and 154. Here, the SQMFF methodology, transferable scaling factors and normal internal coordinates were used together with the Molvib program to compute the harmonic force fields for cation and bisImCl while for bisImPF ${ }_{6}$ only the bands predicted in the $4000-2000 \mathrm{~cm}^{-1}$ region due to the annharmonicity predicted were considered by using recommended scaling factors [30-32]. In figure 6, 7 and 8 are presented the comparisons between the experimental Raman spectra in different wavenumbers regions. Our investigated DILs are composed of two cations bis-imidazolium linked with xylene spacer and two anions of chloride $\left(\mathrm{Cl}^{-}\right)$and hexafluorophosphate $\left(\mathrm{PF}_{6}^{-}\right.$ ). The Raman spectra of both DILs were measured over the frequency range $45-4000 \mathrm{~cm}^{-1}$. In

figures S3, S4 and S5 are presented comparisons between the predicted infrared and Raman spectra of cation, bisImCl and bisImPF 6 . In Table 2 are summarized observed and calculated wavenumbers $\left(\mathrm{cm}^{-1}\right)$ and assignments for cation and ionic liquids bisImCl and bisImPF $\mathrm{In}_{6}$ in gas phase by using B3LYP/6-311++G** calculations. The Raman spectra predicted in activities were converted to intensities. The detailed of the vibrational assignments are given below.

Table 2. Observed and calculated wavenumbers $\left(\mathrm{cm}^{-1}\right)$ and assignments for bisIm cation, and ionic liquids bisImCl and bisImPF $\mathrm{F}_{6}$ in gas phase by using B3LYP/6-311++G** calculations. 


\begin{tabular}{|c|c|c|c|c|c|c|c|}
\hline \multicolumn{3}{|c|}{ bisIm Cation } & \multicolumn{2}{|r|}{ bisImCl } & \multicolumn{3}{|c|}{ bisImPF $_{6}$} \\
\hline $\mathrm{Ra}^{\mathrm{a}}$ & $\mathrm{SQM}^{\mathrm{b}}$ & Assignment ${ }^{\mathrm{a}}$ & $\mathrm{SQM}^{\mathrm{b}}$ & Assignment ${ }^{\mathrm{a}}$ & $\mathrm{Ra}^{\mathrm{a}}$ & $\mathrm{SQM}^{\mathrm{b}}$ & Assignment ${ }^{\mathrm{a}}$ \\
\hline 3153 & 3158 & vC31-H35 & 3156 & $v \mathrm{C} 31-\mathrm{H} 35$ & 3180 & 3028 & $v \mathrm{C}-\mathrm{H}(\mathrm{R} 5)$ \\
\hline & 3158 & $v \mathrm{C} 4-\mathrm{H} 9$ & 3156 & $v \mathrm{C} 4-\mathrm{H} 9$ & 3163 & 3028 & $v C-H(R 5)$ \\
\hline 3146 & 3140 & vC30-H33 & 3138 & vC34-H37 & 3143 & 3018 & $v \mathrm{C}-\mathrm{H}(\mathrm{R} 5)$ \\
\hline & 3140 & $v \mathrm{C} 2-\mathrm{H} 15$ & 3138 & $v \mathrm{C} 5-\mathrm{H} 8$ & 3118 & 3011 & $v \mathrm{C}-\mathrm{H}(\mathrm{R} 5)$ \\
\hline & 3138 & vC34-H37 & 3042 & $v \mathrm{C} 17-\mathrm{H} 20$ & 3084 & 3011 & vC-H(R5) \\
\hline 3111 & 3138 & $v \mathrm{C} 5-\mathrm{H} 8$ & 3035 & $v \mathrm{C} 18-\mathrm{H} 22$ & 3074 & 2959 & vC-H(R5) \\
\hline 3098 & 3052 & $v \mathrm{C} 18-\mathrm{H} 22$ & 3031 & $\mathrm{vC} 19-\mathrm{H} 23$ & 3069 & 2956 & $v \mathrm{C}-\mathrm{H}(\mathrm{R} 6)$ \\
\hline 3071 & 3049 & $v \mathrm{C} 19-\mathrm{H} 23$ & 3027 & $v_{\mathrm{a}} \mathrm{CH}_{3}(\mathrm{C} 36)$ & 3055 & 2929 & $v \mathrm{C}-\mathrm{H}(\mathrm{R} 6)$ \\
\hline 3067 & 3039 & $\mathrm{vC} 21-\mathrm{H} 24$ & 3027 & $v_{\mathrm{a}} \mathrm{CH}_{3}(\mathrm{C} 6)$ & 3051 & 2915 & vC-H(R6) \\
\hline 3059 & 3036 & $\mathrm{vC17- \textrm {H } 2 0}$ & 3018 & $v \mathrm{C} 21-\mathrm{H} 24$ & 3046 & 2912 & $v_{\mathrm{a}} \mathrm{CH}_{3}$ \\
\hline 3043 & 3036 & $v_{\mathrm{a}} \mathrm{CH}_{3}(\mathrm{C} 36)$ & 3000 & $v_{\mathrm{a}} \mathrm{CH}_{3}(\mathrm{C} 36)$ & 3041 & 2910 & vC-H(R6) \\
\hline 3029 & 3036 & $v_{\mathrm{a}} \mathrm{CH}_{3}(\mathrm{C} 6)$ & 3000 & $v_{\mathrm{a}} \mathrm{CH}_{3}(\mathrm{C} 6)$ & 3030 & 2910 & $\mathrm{v}_{\mathrm{a}} \mathrm{CH}_{3}$ \\
\hline 3020 & 3023 & $v_{\mathrm{a}} \mathrm{CH}_{3}(\mathrm{C} 36)$ & 2970 & $v_{\mathrm{a}} \mathrm{CH}_{2}(\mathrm{C} 26)$ & 3023 & 2885 & $v_{\mathrm{a}} \mathrm{CH}_{3}$ \\
\hline 3013 & 3023 & $v_{\mathrm{a}} \mathrm{CH}_{3}(\mathrm{C} 6)$ & 2970 & $v_{\mathrm{a}} \mathrm{CH}_{2}(\mathrm{C} 7)$ & 3007 & 2882 & $v_{\mathrm{a}} \mathrm{CH}_{2}$ \\
\hline 3009 & 2992 & $v_{\mathrm{a}} \mathrm{CH}_{2}(\mathrm{C} 7)$ & 2931 & $v_{\mathrm{s}} \mathrm{CH}_{3}(\mathrm{C} 36)$ & 2989 & 2882 & $v_{\mathrm{a}} \mathrm{CH}_{2}$ \\
\hline 2989 & 2992 & $\mathrm{v}_{\mathrm{a}} \mathrm{CH}_{2}(\mathrm{C} 26)$ & 2931 & $v_{\mathrm{s}} \mathrm{CH}_{3}(\mathrm{C} 6)$ & 2981 & 2871 & $v_{\mathrm{a}} \mathrm{CH}_{2}$ \\
\hline 2958 & 2947 & $v_{\mathrm{s}} \mathrm{CH}_{2}(\mathrm{C} 26)$ & 2877 & $v_{\mathrm{s}} \mathrm{CH}_{2}(\mathrm{C} 7)$ & 2976 & 2826 & $v_{\mathrm{s}} \mathrm{CH}_{2}$ \\
\hline 2948 & 2947 & $v_{\mathrm{s}} \mathrm{CH}_{2}(\mathrm{C} 7)$ & 2876 & $v_{\mathrm{s}} \mathrm{CH}_{2}(\mathrm{C} 26)$ & 2965 & 2826 & $v_{\mathrm{s}} \mathrm{CH}_{2}$ \\
\hline 2876 & 2944 & $v_{\mathrm{s}} \mathrm{CH}_{3}(\mathrm{C} 36)$ & 2653 & vC $30-\mathrm{H} 33$ & 2895 & 2814 & $v_{\mathrm{s}} \mathrm{CH}_{3}$ \\
\hline 2817 & 2944 & $v_{\mathrm{s}} \mathrm{CH}_{3}(\mathrm{C} 6)$ & 2602 & vC2-H15 & 2844 & 2812 & $v_{s} \mathrm{CH}_{3}$ \\
\hline & & & & & & 1656 & $v \mathrm{C}=\mathrm{C}(\mathrm{R} 6)$ \\
\hline & & & & & 1618 & 1621 & $v \mathrm{C}=\mathrm{C}(\mathrm{R} 6)$ \\
\hline & & & & & & 1610 & $v \mathrm{C}=\mathrm{C}(\mathrm{R} 5)$ \\
\hline 1615 & 1599 & $v \mathrm{C} 17-\mathrm{C} 19$ & 1601 & $v \mathrm{C} 17-\mathrm{C} 19$ & 1607 & 1607 & $v \mathrm{C}=\mathrm{C}(\mathrm{R} 5)$ \\
\hline 1583 & 1563 & $\begin{array}{l}\nu \mathrm{C} 16-\mathrm{C} 18 \\
\nu \mathrm{C} 21-\mathrm{C} 25 \\
{ }^{2} \mathrm{C} 19-\mathrm{C} 25\end{array}$ & 1562 & $\begin{array}{l}\nu \mathrm{C} 16-\mathrm{C} 18 \\
v \mathrm{C} 21-\mathrm{C} 25\end{array}$ & 1585 & 1592 & $\beta C-H(R 5)$ \\
\hline 1559 & 1553 & $v \mathrm{C} 4-\mathrm{C} 5$ & 1548 & $v \mathrm{C} 4-\mathrm{C} 5$ & 1563 & 1590 & $\beta C-H(R 5)$ \\
\hline 1550 & 1553 & vC31-C34 & 1548 & vC31-C34 & 1557 & 1547 & $\beta C-H(R 6)$ \\
\hline 1531 & 1531 & $v \mathrm{~N} 3-\mathrm{C} 2$ & 1530 & $v \mathrm{~N} 27-\mathrm{C} 30$ & 1522 & 1515 & $\delta_{\mathrm{a}} \mathrm{CH}_{3}$ \\
\hline & 1530 & $v \mathrm{~N} 27-\mathrm{C} 30$ & 1525 & $v \mathrm{~N} 3-\mathrm{C} 2$ & & 1512 & $\delta_{\mathrm{a}} \mathrm{CH}_{3}$ \\
\hline 1468 & 1500 & $\beta \mathrm{C} 17-\mathrm{H} 20$ & 1499 & $\beta \mathrm{C} 17-\mathrm{H} 20$ & & 1499 & $\delta_{\mathrm{a}} \mathrm{CH}_{3}$ \\
\hline & & & & & 1496 & 1496 & $\delta_{\mathrm{a}} \mathrm{CH}_{3}$ \\
\hline & & & & & & 1495 & $\delta \mathrm{CH}_{2}$ \\
\hline & & & & & & 1490 & $\delta \mathrm{CH}_{2}$ \\
\hline & & & & & 1468 & 1469 & $\delta_{\mathrm{s}} \mathrm{CH}_{3}$ \\
\hline & & & & & & 1464 & $\delta_{\mathrm{s}} \mathrm{CH}_{3}$ \\
\hline 1452 & 1448 & $\delta_{\mathrm{a}} \mathrm{CH}_{3}(\mathrm{C} 36)$ & 1450 & $\delta_{\mathrm{a}} \mathrm{CH}_{3}(\mathrm{C} 6)$ & 1455 & 1459 & $\beta C-H(R 6)$ \\
\hline 1446 & 1448 & $\delta_{\mathrm{a}} \mathrm{CH}_{3}(\mathrm{C} 6)$ & 1450 & $\delta_{\mathrm{a}} \mathrm{CH}_{3}(\mathrm{C} 36)$ & & 1441 & $v \mathrm{C}-\mathrm{N}(\mathrm{A} 5)$ \\
\hline 1428 & 1433 & $\begin{array}{l}\delta \mathrm{CH}_{2}(\mathrm{C} 26) \\
\delta \mathrm{CH}_{2}(\mathrm{C} 7)\end{array}$ & 1432 & $\begin{array}{l}\delta \mathrm{CH}_{2}(\mathrm{C} 7) \\
\delta \mathrm{CH}_{2}(\mathrm{C} 26)\end{array}$ & 1431 & 1440 & $v \mathrm{C}-\mathrm{N}(\mathrm{A} 5)$ \\
\hline
\end{tabular}




\begin{tabular}{|c|c|c|c|c|c|c|c|}
\hline 1425 & 1430 & $\begin{array}{l}\delta \mathrm{CH}_{2}(\mathrm{C} 7) \\
\delta \mathrm{CH}_{2}(\mathrm{C} 26)\end{array}$ & 1430 & $\delta \mathrm{CH}_{2}(\mathrm{C} 26)$ & 1418 & 1417 & wagCH${ }_{2}$ \\
\hline \multirow[t]{2}{*}{1418} & 1420 & $\delta_{\mathrm{a}} \mathrm{CH}_{3}(\mathrm{C} 6)$ & 1428 & $\delta_{\mathrm{a}} \mathrm{CH}_{3}(\mathrm{C} 36)$ & 1406 & 1402 & $\rho \mathrm{CH}_{2}$ \\
\hline & 1420 & $\delta_{\mathrm{a}} \mathrm{CH}_{3}(\mathrm{C} 36)$ & 1428 & $\delta_{\mathrm{a}} \mathrm{CH}_{3}(\mathrm{C} 6)$ & 1392 & 1379 & wagCH $_{2}$ \\
\hline 1407 & 1411 & $\begin{array}{l}v \mathrm{C} 18-\mathrm{C} 21 \\
v \mathrm{C} 17-\mathrm{C} 19\end{array}$ & 1414 & $v \mathrm{C} 18-\mathrm{C} 21$ & 1384 & 1374 & $\rho \mathrm{CH}_{2}$ \\
\hline 1404 & 1399 & $\begin{array}{l}\text { wagCH } \\
\text { (C26) } \\
\text { wagCH}_{2}(\mathrm{C} 7)\end{array}$ & 1402 & $\delta \mathrm{CH}_{2}(\mathrm{C} 7)$ & 1377 & 1354 & $\beta C-H(A 6)$ \\
\hline 1399 & 1399 & $\delta_{\mathrm{s}} \mathrm{CH}_{3}(\mathrm{C} 36)$ & 1402 & $\begin{array}{l}\delta \mathrm{CH}_{2}(\mathrm{C} 26) \\
w^{2} C_{2}(\mathrm{C} 26)\end{array}$ & 1369 & 1343 & $\beta \mathrm{C}-\mathrm{H}(\mathrm{A} 6)$ \\
\hline 1389 & 1394 & $\delta_{\mathrm{s}} \mathrm{CH}_{3}(\mathrm{C} 6)$ & 1394 & $\delta_{\mathrm{s}} \mathrm{CH}_{3}(\mathrm{C} 6)$ & 1342 & 1341 & $v \mathrm{C}-\mathrm{N}$ \\
\hline 1385 & 1393 & $\begin{array}{l}\delta_{\mathrm{s}} \mathrm{CH}_{3}(\mathrm{C} 36) \\
\delta_{\mathrm{s}} \mathrm{CH}_{3}(\mathrm{C} 6)\end{array}$ & 1394 & $\delta_{\mathrm{s}} \mathrm{CH}_{3}(\mathrm{C} 36)$ & 1333 & 1332 & $v \mathrm{C}-\mathrm{N}$ \\
\hline \multirow[t]{3}{*}{1359} & 1359 & $\mathrm{vN} 32-\mathrm{C} 30$ & 1372 & wagCH $_{2}(\mathrm{C} 7)$ & 1309 & 1313 & $\beta \mathrm{C}-\mathrm{H}(\mathrm{R} 5)$ \\
\hline & 1359 & $v \mathrm{~N} 1-\mathrm{C} 2$ & 1368 & wagCH$_{2}(\mathrm{C} 26)$ & 1287 & 1307 & $\beta C-H($ R5) \\
\hline & 1351 & $\begin{array}{l}\text { wagCH }{ }_{2}(\mathrm{C} 7) \\
\text { wagCH }_{2}(\mathrm{C} 26)\end{array}$ & 1341 & $v \mathrm{~N} 32-\mathrm{C} 34$ & 1237 & 1231 & $\beta C-H(R 6)$ \\
\hline 1340 & 1343 & $\begin{array}{l}\text { wagCH } \mathrm{C}_{2}(\mathrm{C} 26) \\
\text { wagCH}_{2}(\mathrm{C} 7)\end{array}$ & 1339 & $v \mathrm{~N} 1-\mathrm{C} 5$ & & 1224 & $\beta C-H(R 6)$ \\
\hline 1325 & 1315 & $\begin{array}{l}\beta C 17-\mathrm{H} 20 \\
\beta C 19-\mathrm{H} 23\end{array}$ & 1318 & $\begin{array}{l}\beta \mathrm{C} 18-\mathrm{H} 22 \\
\beta \mathrm{C} 21-\mathrm{H} 24\end{array}$ & 1218 & 1220 & $\rho \mathrm{CH}_{2}$ \\
\hline 1298 & 1298 & $v \mathrm{C} 21-\mathrm{C} 25$ & 1306 & vN32-C36 & 1211 & 1214 & $\beta C-H(R 6)$ \\
\hline 1279 & 1281 & $v N 32-\mathrm{C} 36$ & 1297 & $v \mathrm{~N} 1-\mathrm{C} 6$ & & 1212 & $\beta C-H(R 6)$ \\
\hline \multirow[t]{3}{*}{1279} & 1280 & $v \mathrm{~N} 3-\mathrm{C} 4$ & 1288 & $v \mathrm{C} 21-\mathrm{C} 25$ & 1189 & 1176 & $\beta \mathrm{C}-\mathrm{H}(\mathrm{R} 5)$ \\
\hline & 1267 & $\beta \mathrm{C} 2-\mathrm{H} 15$ & 1279 & $\beta \mathrm{C} 30-\mathrm{H} 33$ & 1169 & 1174 & $\beta \mathrm{C}-\mathrm{H}(\mathrm{R} 5)$ \\
\hline & 1257 & $\beta C 2-\mathrm{H} 15$ & 1271 & $\beta \mathrm{C} 2-\mathrm{H} 15$ & 1163 & 1158 & $\rho \mathrm{CH}_{3}$ \\
\hline 1215 & 1201 & $\beta \mathrm{R}_{1}(\mathrm{~A} 3) \rho \mathrm{CH}_{2}(\mathrm{C} 7)$ & 1213 & $\rho \mathrm{CH}_{2}(\mathrm{C} 7)$ & & 1157 & $\rho \mathrm{CH}_{3}$ \\
\hline 1199 & 1194 & $\beta \mathrm{R}_{1}(\mathrm{~A} 3) \rho \mathrm{CH}_{2}(\mathrm{C} 7)$ & 1196 & $\rho \mathrm{CH}_{2}(\mathrm{C} 26)$ & 1147 & 1148 & $\beta C-H($ R6) \\
\hline 1189 & 1188 & $\begin{array}{l}\rho \mathrm{CH}_{2}(\mathrm{C} 26) \\
\rho \mathrm{CH}_{2}(\mathrm{C} 7)\end{array}$ & 1193 & $\beta \mathrm{R}_{1}(\mathrm{~A} 3)$ & & 1131 & $\beta C-H(R 5)$ \\
\hline 1189 & 1183 & $\begin{array}{l}\beta \mathrm{C} 19-\mathrm{H} 23 \\
\beta \mathrm{C} 17-\mathrm{H} 20\end{array}$ & 1185 & $\begin{array}{l}\beta \mathrm{C} 17-\mathrm{H} 20 \\
\beta \mathrm{C} 19-\mathrm{H} 23\end{array}$ & 1122 & 1122 & $\beta C-H(R 5)$ \\
\hline 1165 & 1171 & $v \mathrm{C} 26-\mathrm{C} 25$ & 1172 & $v \mathrm{C} 26-\mathrm{C} 25$ & 1111 & 1108 & $\rho \mathrm{CH}_{3}$ \\
\hline \multirow[t]{2}{*}{1124} & 1131 & $\beta \mathrm{C} 2-\mathrm{H} 15$ & 1145 & $v \mathrm{~N} 27-\mathrm{C} 26$ & 1102 & 1107 & $\rho \mathrm{CH}_{3}$ \\
\hline & 1131 & $\beta \mathrm{C} 30-\mathrm{H} 33$ & 1143 & $v \mathrm{~N} 3-\mathrm{C} 7$ & 1043 & 1042 & $\beta \mathrm{R}_{1}(\mathrm{R} 5)$ \\
\hline 1116 & 1117 & $\rho^{\prime} \mathrm{CH}_{3}(\mathrm{C} 6)$ & 1123 & $\rho^{\prime} \mathrm{CH}_{3}(\mathrm{C} 36)$ & 1036 & 1039 & $\beta \mathrm{R}_{1}(\mathrm{R} 5)$ \\
\hline 1116 & 1117 & $\rho^{\prime} \mathrm{CH}_{3}(\mathrm{C} 36)$ & 1123 & $\rho^{\prime} \mathrm{CH}_{3}(\mathrm{C} 6)$ & 1036 & 1038 & $\beta \mathrm{R}_{2}(\mathrm{R} 5)$ \\
\hline 1116 & 1110 & vC18-C21 & 1108 & $\begin{array}{l}v \mathrm{C} 18-\mathrm{C} 21 \\
\beta \mathrm{C} 21-\mathrm{H} 24\end{array}$ & 1036 & 1037 & $\beta \mathrm{R}_{1}(\mathrm{R} 6)$ \\
\hline 1092 & 1093 & $\beta \mathrm{C} 34-\mathrm{H} 37 \beta \mathrm{C} 5-\mathrm{H} 8$ & 1078 & $\beta \mathrm{C} 4-\mathrm{H} 9 \beta \mathrm{C} 5-\mathrm{H} 8$ & 1023 & 1034 & $\beta \mathrm{R}_{2}$ (R5) \\
\hline 1092 & 1092 & $\beta \mathrm{C} 4-\mathrm{H} 9 \beta \mathrm{C} 31-\mathrm{H} 35$ & 1078 & $\beta C 31-\mathrm{H} 35 \beta \mathrm{C} 34-\mathrm{H} 37$ & 1014 & 1014 & $\gamma \mathrm{C}-\mathrm{H}(\mathrm{R} 6)$ \\
\hline \multirow[t]{2}{*}{1083} & 1068 & $\rho \mathrm{CH}_{3}(\mathrm{C} 6)$ & 1060 & $\rho \mathrm{CH}_{3}(\mathrm{C} 6) \vee \mathrm{N} 1-\mathrm{C} 2$ & 988 & 973 & $\gamma \mathrm{C}-\mathrm{H}(\mathrm{R} 6)$ \\
\hline & 1068 & $\rho \mathrm{CH}_{3}(\mathrm{C} 36)$ & 1060 & vN32-C30 & & 967 & $\gamma \mathrm{C}-\mathrm{H}(\mathrm{R} 6)$ \\
\hline 1029 & 1017 & $\beta \mathrm{R}_{1}(\mathrm{~A} 3)$ & 1021 & $\beta \mathrm{R}_{1}(\mathrm{~A} 1)$ & 938 & 946 & $\tau w \mathrm{wCH}_{2}$ \\
\hline
\end{tabular}




\begin{tabular}{|c|c|c|c|c|c|c|c|}
\hline 1019 & 1017 & $\beta R_{1}(\mathrm{~A} 3)$ & 1020 & $\beta R_{1}(\mathrm{~A} 2)$ & 915 & 910 & $\gamma \mathrm{C}-\mathrm{H}(\mathrm{R} 5)$ \\
\hline 1019 & 1016 & $\beta \mathrm{R}_{2}(\mathrm{~A} 1) \beta \mathrm{R}_{2}(\mathrm{~A} 2)$ & 1019 & $\beta R_{1}(\mathrm{~A} 3)$ & & 900 & $\gamma \mathrm{C}-\mathrm{H}(\mathrm{R} 5)$ \\
\hline 1009 & 1006 & $v \mathrm{~N} 32-\mathrm{C} 34$ & 1012 & $\gamma \mathrm{C} 17-\mathrm{H} 20$ & 888 & 889 & $\gamma \mathrm{C}-\mathrm{H}(\mathrm{R} 5)$ \\
\hline 1009 & 1006 & $v \mathrm{~N} 1-\mathrm{C} 5 v \mathrm{~N} 27-\mathrm{C} 31$ & 993 & $v \mathrm{~N} 1-\mathrm{C} 5 \beta \mathrm{R}_{2}(\mathrm{~A} 1)$ & & 882 & $\gamma \mathrm{C}-\mathrm{H}(\mathrm{R} 5)$ \\
\hline 989 & 987 & $\begin{array}{l}\gamma \mathrm{C} 18-\mathrm{H} 22 \\
\gamma \mathrm{C} 21-\mathrm{H} 24\end{array}$ & 992 & $\begin{array}{l}v \mathrm{~N} 32-\mathrm{C} 34 \\
\beta \mathrm{R}_{2}(\mathrm{~A} 2)\end{array}$ & 865 & 859 & $\gamma \mathrm{C}-\mathrm{H}(\mathrm{R} 6)$ \\
\hline 951 & 977 & $\gamma \mathrm{C} 19-\mathrm{H} 23$ & 971 & $\gamma \mathrm{C} 30-\mathrm{H} 33$ & & 856 & $\gamma \mathrm{C}-\mathrm{H}(\mathrm{R} 5)$ \\
\hline 882 & 896 & $\begin{array}{l}\tau \mathrm{wCH}_{2}(\mathrm{C} 26) \\
\tau \mathrm{wCH}_{2}(\mathrm{C} 7)\end{array}$ & 968 & $\gamma \mathrm{C} 2-\mathrm{H} 15$ & 843 & 850 & $v_{\mathrm{a}} \mathrm{PF}_{6}$ \\
\hline 860 & 874 & $\gamma \mathrm{C} 34-\mathrm{H} 37$ & 952 & $\gamma \mathrm{C} 21-\mathrm{H} 24 \gamma \mathrm{C} 18-\mathrm{H} 22$ & 836 & 845 & $v_{\mathrm{a}} \mathrm{PF}_{6}$ \\
\hline 860 & 874 & $\gamma \mathrm{C} 5-\mathrm{H} 8$ & 909 & $\tau \mathrm{wCH}_{2}(\mathrm{C} 26)$ & 830 & 844 & $\gamma \mathrm{C}-\mathrm{H}(\mathrm{R} 6)$ \\
\hline \multirow[t]{2}{*}{854} & 864 & $\tau \mathrm{wCH}_{2}(\mathrm{C} 26)$ & 877 & $\tau \mathrm{wCH}_{2}(\mathrm{C} 7)$ & 827 & 827 & $v_{\mathrm{a}} \mathrm{PF}_{6}$ \\
\hline & 860 & $\gamma \mathrm{C} 18-\mathrm{H} 22$ & 869 & $\gamma \mathrm{C} 19-\mathrm{H} 23$ & 815 & 817 & $v_{\mathrm{a}} \mathrm{PF}_{6}$ \\
\hline 848 & 846 & $\gamma \mathrm{C} 17-\mathrm{H} 20$ & 844 & $\gamma \mathrm{C} 31-\mathrm{H} 35 \gamma \mathrm{C} 4-\mathrm{H} 9$ & & 814 & $v_{\mathrm{a}} \mathrm{PF}_{6}$ \\
\hline 839 & 835 & $\gamma \mathrm{C} 2-\mathrm{H} 15$ & 841 & $\gamma \mathrm{C} 4-\mathrm{H} 9$ & & 813 & $\gamma \mathrm{C}-\mathrm{H}(\mathrm{R} 6)$ \\
\hline 832 & 821 & $\gamma \mathrm{C} 2-\mathrm{H} 15$ & 836 & $\gamma \mathrm{C} 21-\mathrm{H} 24 \gamma \mathrm{C} 18-\mathrm{H} 22$ & 806 & 809 & $v_{\mathrm{a}} \mathrm{PF}_{6}$ \\
\hline 810 & 819 & $\gamma \mathrm{C} 30-\mathrm{H} 33$ & 827 & $v \mathrm{C} 16-\mathrm{C} 17 v \mathrm{C} 19-\mathrm{C} 25$ & 769 & 760 & $\gamma \mathrm{C}-\mathrm{H}(\mathrm{R} 5)$ \\
\hline 780 & 767 & $\tau \mathrm{R}_{1}(\mathrm{~A} 3)$ & 770 & $\tau \mathrm{R}_{1}(\mathrm{~A} 3)$ & 741 & 758 & $\gamma \mathrm{C}-\mathrm{H}(\mathrm{R} 5)$ \\
\hline 772 & 765 & $\begin{array}{l}v \mathrm{C} 26-\mathrm{C} 25 \\
v \mathrm{C} 7-\mathrm{C} 16\end{array}$ & 761 & $\delta \mathrm{N} 3 \mathrm{C} 7 \mathrm{C} 16$ & 738 & 739 & $\gamma \mathrm{C}-\mathrm{H}(\mathrm{R} 5)$ \\
\hline 767 & 745 & $\gamma \mathrm{C} 4-\mathrm{H} 9$ & 725 & $\gamma \mathrm{C} 34-\mathrm{H} 37$ & 720 & 736 & $\gamma \mathrm{C}-\mathrm{H}(\mathrm{R} 6)$ \\
\hline 767 & 745 & $\gamma \mathrm{C} 31-\mathrm{H} 35$ & 724 & $\gamma \mathrm{C} 5-\mathrm{H} 8$ & 702 & 709 & $\tau \mathrm{R}_{1}(\mathrm{R} 6)$ \\
\hline 704 & 713 & $v \mathrm{~N} 27-\mathrm{C} 26 v \mathrm{~N} 3-\mathrm{C} 7$ & 716 & $v \mathrm{~N} 27-\mathrm{C} 26 v \mathrm{~N} 3-\mathrm{C} 7$ & 680 & 680 & $\tau \mathrm{R}_{1}(\mathrm{R} 5)$ \\
\hline \multirow[t]{2}{*}{656} & 686 & $\tau \mathrm{R}_{1}$ (A3) & 693 & $\tau \mathrm{R}_{1}(\mathrm{~A} 3)$ & 672 & 679 & $\tau \mathrm{R}_{1}(\mathrm{R} 5)$ \\
\hline & & & 656 & $v \mathrm{~N} 32-\mathrm{C} 36 v \mathrm{~N} 1-\mathrm{C} 6$ & 667 & 675 & $v_{\mathrm{s}} \mathrm{PF}_{6}$ \\
\hline 641 & 648 & $\beta \mathrm{R}_{2}(\mathrm{~A} 3)$ & 652 & $\tau \mathrm{R}_{1}(\mathrm{~A} 3) \tau \mathrm{R}_{2}(\mathrm{~A} 1)$ & & 655 & $\tau \mathrm{R}_{2}$ (R5) \\
\hline 641 & 646 & $\tau \mathrm{R}_{1}(\mathrm{~A} 3)$ & 645 & $\beta \mathrm{R}_{2}(\mathrm{~A} 3)$ & 649 & 653 & $\beta \mathrm{R}_{3}(\mathrm{R} 6)$ \\
\hline \multirow[t]{3}{*}{641} & 641 & vN1-C6vN32-C36 & & & 643 & 639 & $\tau \mathrm{R}_{2}$ (R5) \\
\hline & & & & & 629 & 633 & $v \mathrm{~N}-\mathrm{C}$ \\
\hline & & & & & 621 & 625 & $v \mathrm{~N}-\mathrm{C}$ \\
\hline 617 & 615 & $\tau \mathrm{R}_{1}(\mathrm{~A} 2)$ & 612 & $\tau \mathrm{R}_{1}(\mathrm{~A} 2)$ & 616 & 618 & $v \mathrm{~N}-\mathrm{C}$ \\
\hline \multirow[t]{2}{*}{611} & 615 & $\tau \mathrm{R}_{1}(\mathrm{~A} 1)$ & 612 & $\tau \mathrm{R}_{1}(\mathrm{~A} 1)$ & 572 & 568 & $\mathrm{vC}-\mathrm{C}$ \\
\hline & 603 & $\tau \mathrm{R}_{2}(\mathrm{~A} 2)$ & 603 & $\tau \mathrm{R}_{2}(\mathrm{~A} 1)$ & 548 & 535 & $v_{\mathrm{a}} \mathrm{PF}_{6}$ \\
\hline 587 & 600 & $\tau \mathrm{R}_{2}(\mathrm{~A} 1)$ & 603 & $\tau \mathrm{R}_{2}$ (A2) & 548 & 532 & $v_{\mathrm{a}} \mathrm{PF}_{6}$ \\
\hline \multirow[t]{8}{*}{544} & 556 & $\beta \mathrm{R}_{3}$ (A3) & 542 & $\beta \mathrm{R}_{3}(\mathrm{~A} 3)$ & 532 & 528 & $\delta_{\mathrm{a}} \mathrm{FPF}$ \\
\hline & & & & & & 527 & $\delta_{\mathrm{a}} \mathrm{FPF}$ \\
\hline & & & & & & 526 & $\delta_{\mathrm{a}} \mathrm{FPF}$ \\
\hline & & & & & & 526 & $\delta_{\mathrm{a}} \mathrm{FPF}$ \\
\hline & & & & & & 525 & $\delta_{\mathrm{a}} \mathrm{FPF}$ \\
\hline & & & & & & 524 & $\delta_{\mathrm{a}} \mathrm{FPF}$ \\
\hline & & & & & & 522 & $\delta_{\mathrm{a}} \mathrm{FPF}$ \\
\hline & & & & & & 515 & $v_{\mathrm{a}} \mathrm{PF}_{6}$ \\
\hline \multirow[t]{2}{*}{510} & 496 & $\tau \mathrm{R}_{3}(\mathrm{~A} 3) \tau \mathrm{R}_{2}(\mathrm{~A} 3)$ & 499 & $\begin{array}{l}\tau \mathrm{R}_{3}(\mathrm{~A} 3) \gamma \mathrm{C} 16-\mathrm{C} 7 \\
\gamma \mathrm{C} 25-\mathrm{C} 26\end{array}$ & 479 & 491 & $v \mathrm{C}-\mathrm{C}$ \\
\hline & & & & & 471 & 444 & $\tau_{\mathrm{w}} \mathrm{PF}_{6}$ \\
\hline
\end{tabular}




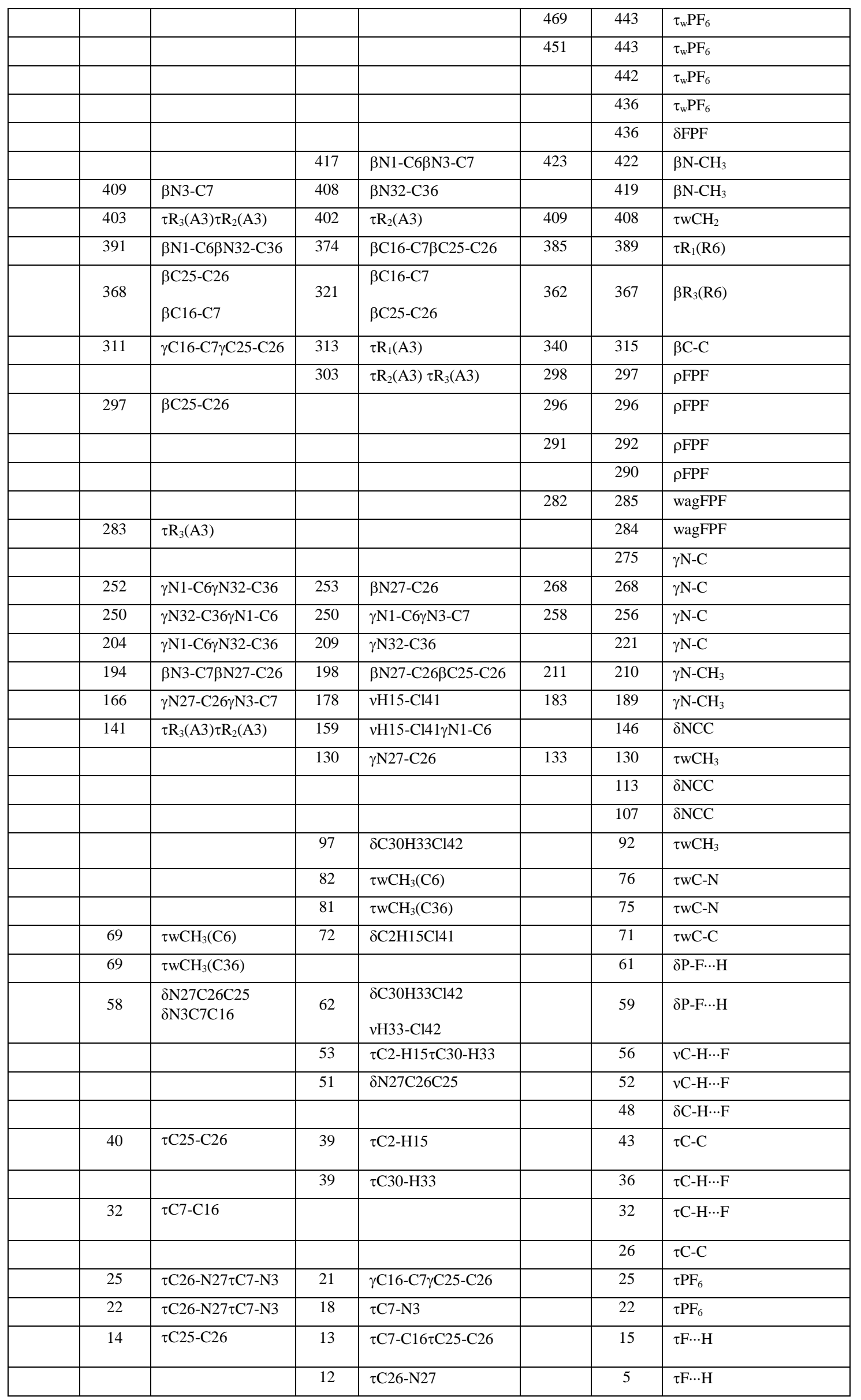


Abbreviations: $v$, stretching; wag, wagging; $\tau$, torsion; $\rho$, rocking; $\tau \mathrm{w}$, twisting; $\delta$, deformation; a, antisymmetric; s, symmetric; a, antisymmetric; s, symmetric; $\left(\mathrm{A}_{1}\right)$, Ring 1; $\left(\mathrm{A}_{2}\right)$, Ring 2, $\left(\mathrm{A}_{3}\right)$, Ring 3.

${ }^{a}$ This work; ${ }^{b}$ From scaled quantum mechanics force field B3LYP/6-311++G** method

\section{C-H vibrations}

Then C-H stretching modes are predicted by SQM calculations in the cation between 3158 and $3036 \mathrm{~cm}^{-1}$ while in bisImCl the $\mathrm{C} 2-\mathrm{H} 15$ and $\mathrm{C} 30-\mathrm{H} 33$ coordinated to the $\mathrm{Cl}$ atoms are predicted in the IR spectra intense at 2653 and $2603 \mathrm{~cm}^{-1}$ different from bisImPF 6 which are predicted at higher wavenumbers. In the Raman spectrum that $\mathrm{C}-\mathrm{H}$ stretching mode in bisImCl is observed with lower intensity (Figure S4). As shown in Figure 6, the symmetric modes at 2817 and $2876 \mathrm{~cm}^{-1}$ in bisImCl and at 2844 and $2895 \mathrm{~cm}^{-1}$ for bisImPF 6 were assigned to the methyl group attached to the imidazolium rings $\mathrm{N}^{+}-\left(\mathrm{CH}_{3}\right)[27,47]$. The bands at $2948,2981,2989 \mathrm{~cm}^{-1}$ for bisImCl and at 2965, 2981, $3007 \mathrm{~cm}^{-1}$ for bisImPF 6 corresponding to the methylene group $\left(-\mathrm{CH}_{2}-\right)$ [27]. While, the anti-symmetric modes of methyl group $\mathrm{N}^{+}-\left(\mathrm{CH}_{3}\right)$ attached to the imidazolium rings appeared at $3013,3029,3043 \mathrm{~cm}^{-1}$ for bisImCl and at $3023,3046 \mathrm{~cm}^{-1}$ for bisImPF 6 . Thus, the $\mathrm{C}-\mathrm{H}$ stretching in imidazole ring are viewed experimentally by the presence of the bands from 3059 to $3153 \mathrm{~cm}^{-1}$ for bisImCl and from 3023 to $3180 \mathrm{~cm}^{-1}$ for bisImPF . The vibrational bands at lower wavenumbers can be referred to $\mathrm{C}(2)-\mathrm{H}$ stretching modes, whereas those at higher wavenumbers can be assigned to the $\mathrm{C}(4,5)-\mathrm{H}$ stretching modes [27, 46,49]. The detailed attributions of these bands for both investigated DILs are reported in Table 2. The C2-H15, C4-H9, C5-H8, C30-H33, C31-H35 and C34-H37 stretching vibrations corresponding to imidazole ring in cation, bisImCl and bisImPF 6 are predicted in expected regions $[46,49]$. On the other hand, the aromatic $\mathrm{C} 17-\mathrm{H} 20, \mathrm{C} 18-\mathrm{H} 22, \mathrm{C} 19-\mathrm{H} 23$ and $\mathrm{C} 21-\mathrm{H} 24$ modes of phenyl ring are predicted in the region of higher wavenumber for cation but for the two ionic liquids are predicted mixed among other stretching modes as observed in Table 2. The vibrational modes corresponding to two methyl groups $\left(\mathrm{N}-\mathrm{CH}_{3}\right)$ are identified as (C6) and (C36) and 
both are predicted in different regions in the three species and, hence, assigned as predicted by calculations.

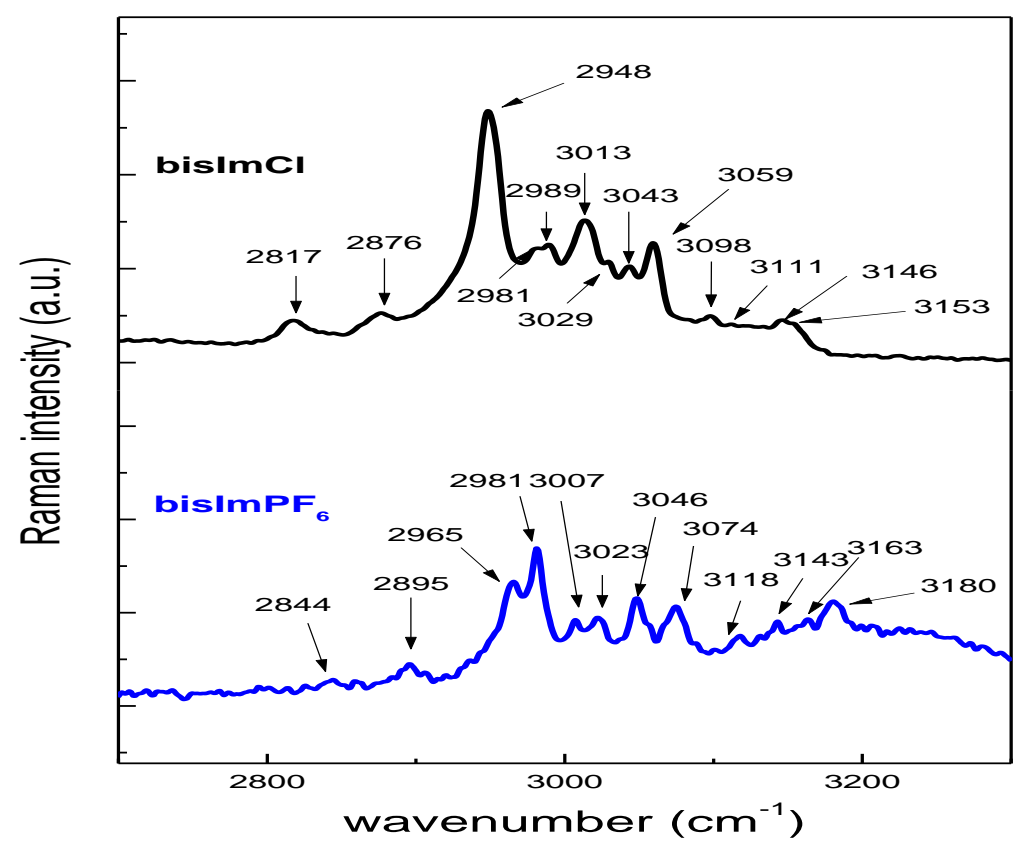

Figure 6. Experimental Raman vibrational spectra of bis $\operatorname{ImCl}$ and bisImPF $\mathrm{I}_{6}$ in the frequency range $2600-3500 \mathrm{~cm}^{-1}$.

\section{$\mathrm{C}=\mathrm{C}, \mathrm{C}-\mathrm{C}$ and $\mathrm{C}-\mathrm{N}$ vibrations}

The $\mathrm{C}=\mathrm{C}$ vibrational frequencies are the significant characteristic bands in the vibrational spectra of phenyl and imidazolium rings, hence, the observed Raman bands at 1616, 1583, 1559 and $1550 \mathrm{~cm}^{-1}$ are assigned to $\mathrm{C}=\mathrm{C}$ vibrations for bis $\operatorname{ImCl}$, and at 1618 and $1607 \mathrm{~cm}^{-1}$ in bisImPF$_{6}($ Figure 7). This is in excellent agreement with the values predicted in our previous works $[46,49]$. 


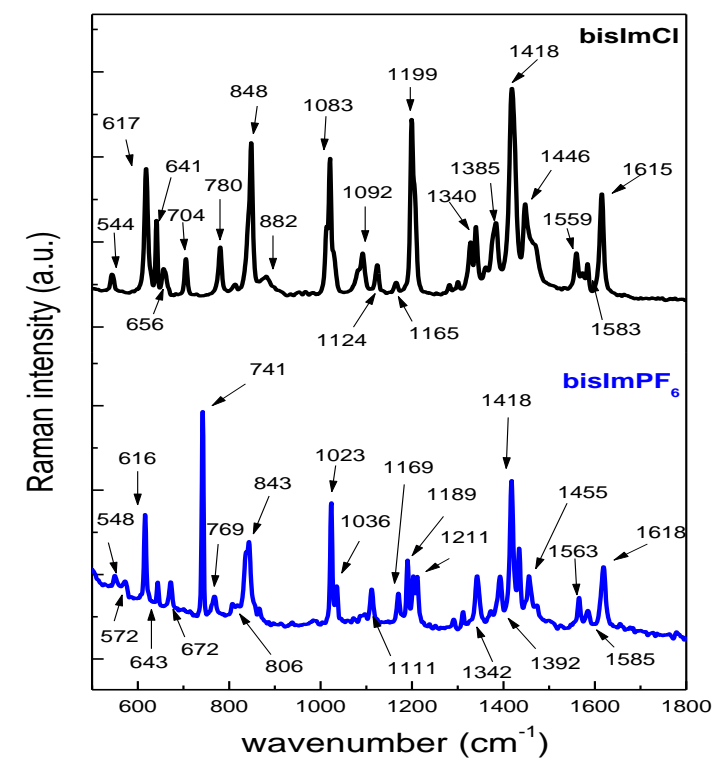

Figure 7. Experimental Raman vibrational spectra of bisImCl and bisImPF 6 in the frequency range $500-1800 \mathrm{~cm}^{-1}$.

In the cation, the $\mathrm{C}-\mathrm{C}, \mathrm{C}-\mathrm{N}$ stretching and in-plane $\mathrm{N}-\mathrm{C}-\mathrm{H}$ bending, related to the imidazole ring and the $\mathrm{C}-\mathrm{C}$ aromatic stretching vibrations covering the spectral range from 1500 to $1110 \mathrm{~cm}^{-1}$. The calculations predict the $\mathrm{N}-\mathrm{C}$ stretching modes in the bis $\mathrm{ImCl}$ at 1530,1525 , $1341,1339,1306,1297,1145$ and $1143 \mathrm{~cm}^{-1}$, hence, they can be assigned in these regions while in bisImPF 6 these modes are predicted at higher wavenumbers. Thus, these modes can be assigned to the Raman bands observed in those regions predicted by calculations. The C2$\mathrm{H} 15$ and C30-H33 bending modes in the cation are predicted at 1267 and $1257 \mathrm{~cm}^{-1}$ while the presence of $\mathrm{Cl}$ atoms in bisImCl produces a shifting of $\mathrm{C} 2-\mathrm{H} 15$ and $\mathrm{C} 30-\mathrm{H} 33$ bending modes toward higher wavenumbers. Hence, these two modes in the chlorinated ionic liquid are predicted at 1279 and $1271 \mathrm{~cm}^{-1}$ while in bisImPF 6 both are predicted at 1176 and $1174 \mathrm{~cm}^{-1}$. For these reasons, the Raman bands observed in these regions can be easily attributed to these vibration modes.

The SQM calculations predict the $\mathrm{C}-\mathrm{N}$ stretching modes corresponding to $\mathrm{N}-\mathrm{CH}_{2}$ (N26-C26 and $\mathrm{N} 3-\mathrm{C} 7$ ) in bisImCl at 1145 and $1143 \mathrm{~cm}^{-1}$ while in bisImPF 6 these modes are predicted at higher wavenumbers. Thus, those modes can be assigned accordingly and, as supported by literature data [52,53]. The C-C stretching vibrations of bis $\mathrm{ImCl}$ are found at 1288, 1193, 1172 and $827 \mathrm{~cm}^{-1}$ while in bisImPF 6 these modes are predicted in approximately the same regions but strongly mixed with bending modes of both five members rings and are in good agreement with those found in the characteristic group frequency tables [46,49]. 


\section{$\mathrm{PF}_{6}$ anion vibrations}

B3LYP/6-311++G** calculations have clearly predicted the vibrations modes of both PF6 groups of bisImPF6. The observed bands of the P-F stretching vibrations in bisImPF 6 DIL have been found to be very strong in the Raman spectra and these appear in the range 900700 and $600-200 \mathrm{~cm}^{-1}$ (Figure 8). The antisymmetric P-F stretching modes are assigned at 843 and $836 \mathrm{~cm}^{-1}$ while the symmetric stretching mode is assigned to the Raman band at 806 $\mathrm{cm}^{-1}$, as was observed in $\left[\mathrm{EMIM}^{+}\right]\left[\mathrm{PF}_{6}^{-}\right]$[37]. The group of bands at 548 and $532 \mathrm{~cm}^{-1}$ can be easily assigned to F-P-F deformations or scissors mode of $\mathrm{PF}_{6}$ while the bands at 471,469 and $451 \mathrm{~cm}^{-1}$ are assigned to torsions of $\mathrm{PF}_{6}$ anion. The bands at 298, 296 and $291 \mathrm{~cm}^{-1}$ are assigned to rocking modes of these groups while the Raman band at $282 \mathrm{~cm}^{-1}$ is assigned to waging modes of these groups [37]. Assignments of the P-F stretching modes have been reported over the range by Talaty et al. [53].

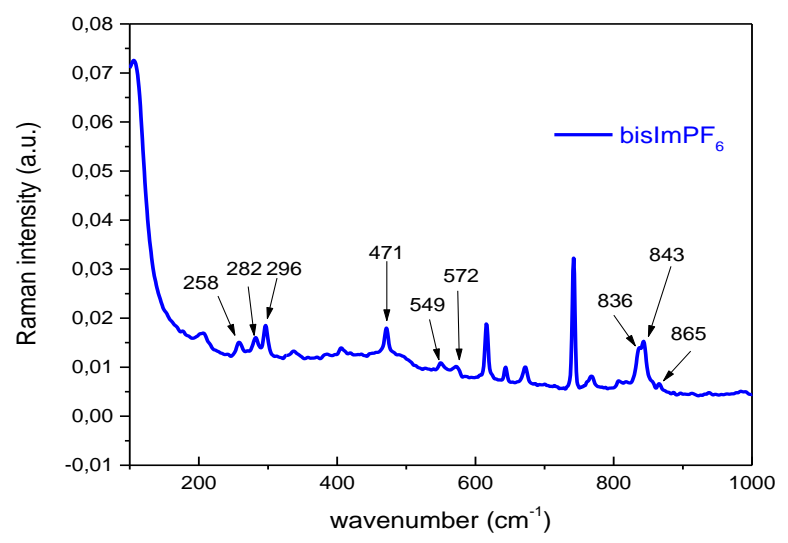

Figure 8. Experimental Raman vibrational spectra of bisImPF $\mathrm{P}_{6}$ in the frequency range 300$1000 \mathrm{~cm}^{-1}$.

\subsection{Force fields}

Scaled internal force constants for $\left[\right.$ bisIm $\left.^{+}\right]$cation and ionic liquid [bisImCl] were calculated because these parameters are useful to predict the forces of different bonds. Thus, the harmonic force fields were used to computed those constants by using B3LYP/6-311++G** calculations. Comparisons of scaled internal force constants obtained for [bisIm $\left.{ }^{+}\right]$cation and ionic liquid [bisImCl] in gas phase can be seen in Table 3 compared with those reported for $\left[\mathrm{EMIM}^{+}\right]\left[\mathrm{PF}_{6}^{-}\right]$[37]. The comparisons between the force constants for cation and [bisImCl] show that the incorporations of two $\mathrm{Cl}$ atoms to cation generate differences important in the 
$f(\nu C-H)_{R 5}$ and $f(\nu C=C)_{R 5}$ force constants and affect slightly to $f\left(\nu C H_{2}\right)$ constants. Obviously, the $\mathrm{Cl}$ atoms due to its electronegativities are coordinated to cation by $\mathrm{C}-\mathrm{H} \cdots \mathrm{Cl}$ bonds producing decreasing in the $f(\nu C-H)_{R 5}$ values while increase the values of $f(\nu C=C)_{R 5}$ force constants. Note that the cation-anion coordination is slightly higher in the ionic liquid $\left[\mathrm{EMIM}^{+}\right]\left[\mathrm{PF}_{6}^{-}\right]$increasing the $f(v C-H)_{R 5}$ constant value to 5.41 mdyn $\AA^{-1}$ and of the $f(v C-N)_{R 5}$ constant to 6.70 mdyn $\AA^{-1}[37]$.

Table 3. Comparisons of scaled internal force constants for [bisIm $\left.{ }^{+}\right]$cation and ionic liquid [bisImCl] in gas phase by using B3LYP/6-311++G** calculations.

\begin{tabular}{|c|c|c|c|}
\hline \multicolumn{4}{|c|}{ B3LYP/6-311++G**Method } \\
\hline Force constants & {$\left[\right.$ bisImCl] ${ }^{\mathrm{a}}$} & {$\left[\text { bisIm }^{+}\right]^{\mathrm{a}}$} & {$\left[\mathrm{EMIM}^{+}\right]\left[\mathrm{PF}_{6}^{-}\right]^{\mathrm{b}}$} \\
\hline$f(v C-H)_{H b o n d}$ & 5.04 & 5.08 & 5.45 \\
\hline$f(v C-H)_{R 5}$ & 4.97 & 5.39 & 5.41 \\
\hline$f\left(v \mathrm{CH}_{2}\right)$ & 4.70 & 4.86 & 4.87 \\
\hline$f\left(v C H_{3}\right)$ & 4.92 & 4.96 & 4.89 \\
\hline$f(v C-N)_{R 5}$ & 6.53 & 6.57 & 6.70 \\
\hline$f(v C-N)$ & 4.32 & 4.13 & 4.34 \\
\hline$f(v C=C)_{R 5}$ & 7.65 & 7.59 & 7.63 \\
\hline$f(v C=C)_{R 6}$ & 6.34 & 6.33 & \\
\hline$f\left(\delta \mathrm{CH}_{2}\right)$ & 0.75 & 0.76 & 0.76 \\
\hline$f\left(\delta \mathrm{CH}_{3}\right)$ & 0.55 & 0.54 & 0.54 \\
\hline
\end{tabular}

Units are mdyn $\AA^{-1}$ for stretching and mdyn $\AA \operatorname{rad}^{-2}$ for angle deformations

${ }^{\mathrm{a}}$ This work, ${ }^{\mathrm{b}}$ From Ref [37].

\subsection{Thermal properties}

The thermal behavior of bisImCl and bisImPF 6 was investigated by means of concomitant TGA/DTA measurements. The experimental DTA data of bisImCl and bisImPF 6 DILs are shown in figure9. Concerning the melting process, it was observed in bisImPF 6 by an endothermic peak at $\sim 230^{\circ} \mathrm{C}$, as result of a change from thermograms baseline. In the case of bisImCl, the DTA peak at the lowest temperature $\left(\sim 280{ }^{\circ} \mathrm{C}\right)$ seems to correspond to the first step of decomposition rather than to the melting process (see TGA results of figure10). 


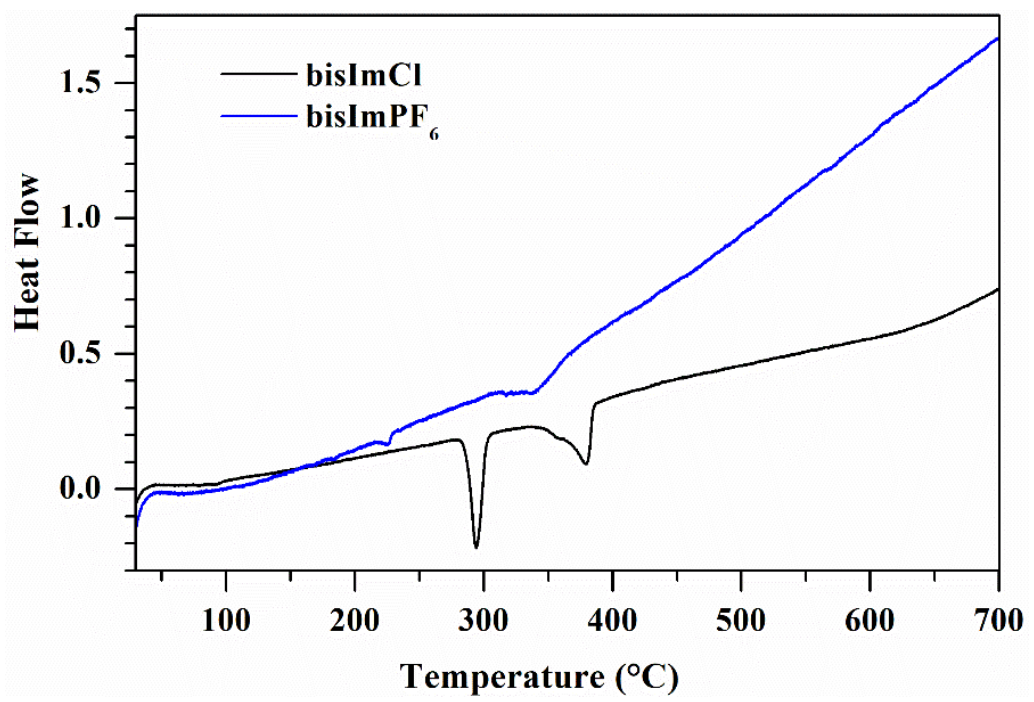

Figure 9. Heat flow (DTA) curves for the investigated bisImCl and bisImPF 6

DILs as a function of temperature.

Additionally, the TGA curve shows a multistep degradation process associated with the thermal decomposition of the $\mathrm{PF}_{6}$ anion in the temperature range of $280-380{ }^{\circ} \mathrm{C}$ and the release next to bisIm cation in the temperature range $380-500{ }^{\circ} \mathrm{C}$, respectively. The TGA study exactly fits and confirms the DTA study.

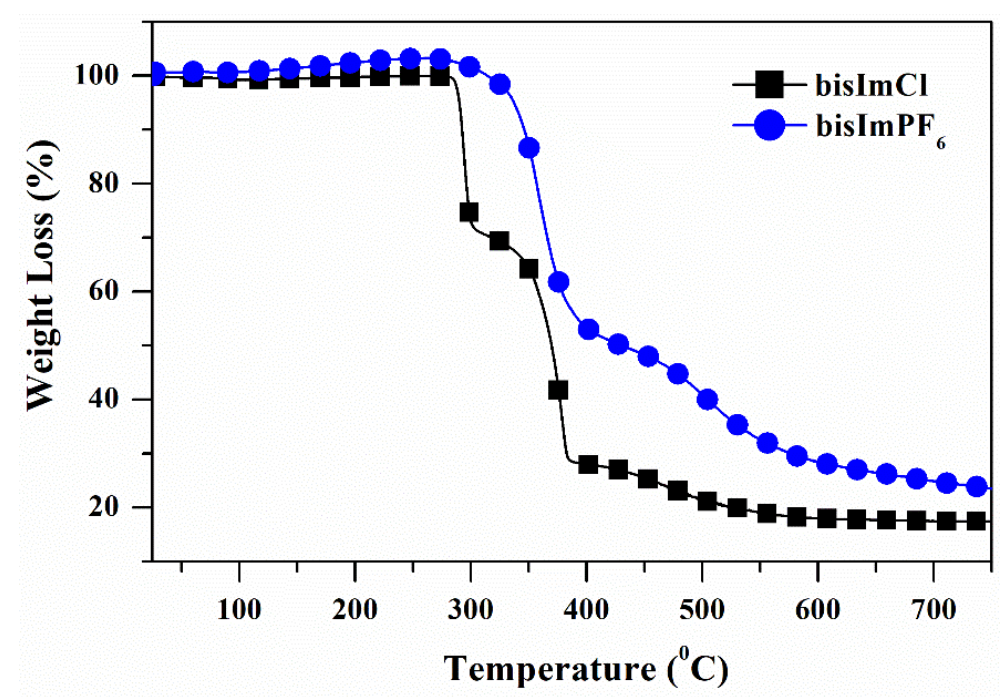

Figure 10. Thermal gravimetric analysis (TGA) for the investigated bisImCl and bisImPF ${ }_{6}$ DILs.

From experimental results, it is clear that bisImCl and bisImPF ${ }_{6}$ DILs are thermally stable at least up to $200^{\circ} \mathrm{C}$ and exhibit two different decomposition temperature values, which are included in the $280-400{ }^{\circ} \mathrm{C}$ range. The decomposition temperature of bis $\operatorname{ImCl}$ is less than bisImPF ${ }_{6}$ DIL. Nature of decomposition of bisimCl is different from bisImPF 6 . From above 
experimental results, it is clear that the anion can affect significantly on decomposition of these DILs and can be explained on basis of intermolecular interaction and coordinating nature of anion. Due to highly coordinating nature of $\mathrm{PF}_{6}$ anion, the decomposition temperature of bisImPF 6 is higher than bisImCl DIL.

\subsection{Electrical properties}

The HRS first hyperpolarizability $\left(\beta_{\mathrm{HRS}}\right)$ can be deduced from electric field-induced second harmonic generation (EFISHG) measurements. Here, the $\beta_{\mathrm{HRS}}$ is related to the HRS intensity for non-polarized incident light and observation of plane-polarized scattered light made perpendicularly to the propagation plane. By using the HRS method, we can obtain several independent tensors for $\beta$ calculation, which is not possible by EFISHG [56].In HRS, the depolarization ratios (DR) can also be calculated. For a non-polarized incident signal, and for the reason that both polarizations are detected with equal sensitivity, the orientational average overßis:

$$
\left\langle\beta_{\mathrm{HRS}}^{2}\right\rangle=\left\langle\beta_{\mathrm{ZZZ}}^{2}\right\rangle+\left\langle\beta_{\mathrm{ZXX}}^{2}\right\rangle
$$

The full expressions of $\left\langle\beta_{\mathrm{ZZZ}}^{2}\right\rangle$ and $\left\langle\beta_{\mathrm{ZXX}}^{2}\right\rangle$ can be obtained from previously reported work [57].The associated DR is defined as:

$$
\mathrm{DR}=\frac{\mathrm{I}_{\mathrm{VV}}^{2 \omega}}{\mathrm{I}_{\mathrm{HV}}^{2 \omega}}=\frac{\left\langle\beta_{\mathrm{ZZZ}}^{2}\right\rangle}{\left\langle\beta_{\mathrm{ZXX}}^{2}\right\rangle}
$$

These two terms are orientational averages of the $\beta_{\mathrm{ijk}}$ tensor. All 10 calculated hyperpolarizability $\beta_{\mathrm{ijk}}$ contributions can be deduced from the direct hyperpolarizability calculations. These HRS invariants are calculated without assuming Kleinman's conditions.

$$
\begin{aligned}
&\left\langle\beta_{\mathrm{zzz}}^{2}\right\rangle= \frac{1}{7} \sum_{\zeta}^{\mathrm{x}, \mathrm{y}, \mathrm{z}} \beta_{\zeta \zeta \zeta}^{2}+\frac{4}{35} \sum_{\zeta \neq \eta}^{\mathrm{x}, \mathrm{y}, \mathrm{z}} \beta_{\zeta \zeta \eta}^{2}+\frac{2}{35} \sum_{\zeta \neq \eta}^{\mathrm{x}, \mathrm{y}, \mathrm{z}} \beta_{\zeta \zeta \zeta} \beta_{\zeta \eta \eta}+\frac{4}{35} \sum_{\zeta \neq \eta}^{\mathrm{x}, \mathrm{y}, \mathrm{z}} \beta_{\eta \zeta \zeta} \beta_{\zeta \zeta \eta} \\
&+\frac{4}{35} \sum_{\zeta \neq \eta}^{\mathrm{x}, \mathrm{y}, \mathrm{z}} \beta_{\zeta \zeta \zeta} \beta_{\eta \eta \zeta}+\frac{1}{35} \sum_{\zeta \neq \eta}^{\mathrm{x}, \mathrm{y}, \mathrm{z}} \beta_{\eta \zeta \zeta}^{2}+\frac{4}{105} \sum_{\zeta \neq \eta \neq \varepsilon}^{\mathrm{x}, \mathrm{y}, \mathrm{z}} \beta_{\zeta \zeta \eta} \beta_{\eta \varepsilon \varepsilon}+\frac{1}{105} \sum_{\zeta \neq \eta \neq \varepsilon}^{\mathrm{x}, \mathrm{y}, \mathrm{z}} \beta_{\eta \zeta \zeta} \beta_{\eta \varepsilon \varepsilon} \\
&+\frac{4}{105} \sum_{\zeta \neq \eta \neq \varepsilon}^{\mathrm{x}, \mathrm{y}, \mathrm{z}} \beta_{\zeta \zeta \eta} \beta_{\varepsilon \varepsilon \eta} \\
&+\frac{2}{105} \sum_{\zeta \neq \eta \neq \varepsilon}^{\mathrm{x}, \mathrm{y}, \mathrm{z}} \beta_{\zeta \eta \varepsilon}^{2}+\frac{4}{105} \sum_{\zeta \neq \eta \neq \varepsilon}^{\mathrm{x}, \mathrm{y}, \mathrm{z}} \beta_{\zeta \eta \varepsilon} \beta_{\eta \zeta \varepsilon}
\end{aligned}
$$




$$
\begin{gathered}
\left\langle\beta_{\mathrm{xzz}}^{2}\right\rangle=\frac{1}{35} \sum_{\zeta}^{\mathrm{x}, \mathrm{y}, \mathrm{z}} \beta_{\zeta \zeta \zeta}^{2}+\frac{4}{105} \sum_{\zeta \neq \eta}^{\mathrm{x}, \mathrm{y}, \mathrm{z}} \beta_{\zeta \zeta \zeta} \beta_{\zeta \eta \eta}-\frac{2}{35} \sum_{\zeta \neq \eta}^{\mathrm{x}, \mathrm{y}, \mathrm{z}} \beta_{\zeta \zeta \zeta} \beta_{\eta \eta \zeta}+\frac{8}{105} \sum_{\zeta \neq \eta}^{\mathrm{x}, \mathrm{y}, \mathrm{z}} \beta_{\zeta \zeta \eta}^{2} \\
\quad+\frac{3}{35} \sum_{\zeta \neq \eta}^{\mathrm{x}, \mathrm{y}, \mathrm{z}} \beta_{\zeta \eta \eta}^{2}-\frac{2}{35} \sum_{\zeta \neq \eta}^{\mathrm{x}, \mathrm{y}, \mathrm{z}} \beta_{\zeta \zeta \eta} \beta_{\eta \zeta \zeta}+\frac{1}{35} \sum_{\zeta \neq \eta}^{\mathrm{x}, \mathrm{y}, \mathrm{z}} \beta_{\zeta \eta \eta} \beta_{\zeta \varepsilon \varepsilon} \\
-\frac{2}{105} \sum_{\zeta \neq \eta \neq \varepsilon}^{\mathrm{x}, \mathrm{y}, \mathrm{z}} \beta_{\zeta \zeta \eta} \beta_{\eta \varepsilon \varepsilon}+\frac{2}{35} \sum_{\zeta \neq \eta \neq \varepsilon}^{\mathrm{x}, \mathrm{y}, \mathrm{z}} \beta_{\zeta \eta \varepsilon}^{2}-\frac{2}{105} \sum_{\zeta \neq \eta \neq \varepsilon}^{\mathrm{x}, \mathrm{y}, \mathrm{z}} \beta_{\zeta \eta \varepsilon} \beta_{\eta \zeta \varepsilon}
\end{gathered}
$$

TheB3LYP and CAM-B3LYP functionalswere adopted for calculating the polarizability $\alpha$, and first hyperpolarizability $\beta$, at the $6-311+\mathrm{G}(\mathrm{d})$ and aug-cc-pVDZ basis sets. The results of the calculation after geometry optimization are reported in Table4. Both DFT functionals showed high $\beta_{\mathrm{HRS}}$ values for both the bisImCl and bisImPF 6 DILs (Table 4). The results show in first the high values of the average polarizability $\langle\alpha\rangle$ obtained by the B3LYP and CAM-B3LYP functionals. The maximum value of $\langle\alpha\rangle$ in bisImPF $\operatorname{Is}_{6}$ is 294.8 a.u. using CAMB3LYP/6-311+G(d) calculation. Small differences in these values are obtained with different functionals and basis sets; however, the observed differences are insignificance.It must be noted that the average polarizability $\langle\alpha\rangle$ is mostly driven by the DILs size while the polarizability anisotropy $|\alpha|$ presents more subtle variations as a function of these DILs.

\begin{tabular}{|c|c|c|c|c|c|c|}
\hline & & \multicolumn{5}{|c|}{ bisImCIDIL } \\
\hline & & $\langle\alpha\rangle$ & $|\alpha|$ & $\beta_{\mathrm{HRS}}$ & DR & $\Delta \varepsilon$ \\
\hline \multirow{2}{*}{ B3LYP } & $6-311+\mathrm{G}(\mathrm{d})$ & 252.74 & 85.54 & 516.69 & 7.43 & 1.96 \\
\hline & aug-cc-pVDZ & 266.34 & 90.33 & 474.55 & 7.49 & 1.99 \\
\hline \multirow{4}{*}{ CAM-B3LYP } & $6-311+G(d)$ & 243.49 & 77.73 & 211.08 & 7.17 & 2.87 \\
\hline & aug-cc-pVDZ & 257.59 & 82.98 & 183.77 & 7.15 & 2.94 \\
\hline & & \multicolumn{5}{|c|}{ bisImPF 6 DIL } \\
\hline & & $\langle\alpha\rangle$ & $|\alpha|$ & $\beta_{\mathrm{HRS}}$ & DR & $\Delta \varepsilon$ \\
\hline \multirow{3}{*}{ B3LYP } & $6-311+G(d)$ & 249.88 & 36.77 & 145.76 & 7.57 & 3.19 \\
\hline & aug-cc-pVDZ & 261.53 & 37.71 & 122.30 & 7.43 & 3.56 \\
\hline & & & & $115.70^{\mathrm{a}}$ & $7.10^{\mathrm{a}}$ & \\
\hline CAM-B3LYP & $6-311+\mathrm{G}(\mathrm{d})$ & 294.80 & 34.24 & 127.74 & 7.51 & 3.37 \\
\hline
\end{tabular}

Table 4: B3LYP and CAM-B3LYP calculations of $\langle\alpha\rangle,|\alpha|, \beta_{\mathrm{HRS}}$, DR in (a.u.) and $\Delta \varepsilon$ in eVusing 6-311+G(d) and aug-cc-pVDZbasis sets for bisImCl and bisImPF 6 DILs. 


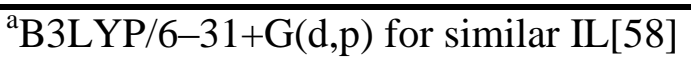

DFT/B3LYP calculation gives the highest $\beta_{\mathrm{HRS}}$ values for bisImCl DIL, the CAM-B3LYP functional shows satisfactory hyperpolarizability results (Table 4and Figure 12). From our previous studies [59-61], it can be state that the CAM-B3LYP functional has shown to predict reliable hyperpolarizability of different compounds.In case of the presence of the $\mathrm{PF}_{6}^{-}$, and using the6-311+G(d) and aug-cc-pVDZbasis sets, the B3LYP functional givesthe lowest values of the mean polarizabilities $\langle\alpha\rangle$. On the other hand, the bisImClshows the highest $\beta_{\mathrm{HRS}}$ values $\left(\beta_{\mathrm{HRS}}=516.6\right.$ a.u.) using the B3LYP/6-311+G(d) calculation. Shkir et al.[62]showed that the hyperpolarizability in ILs strongly depend on cation-anion interactions. In our ILs, the $\beta_{\mathrm{HRS}}$ of bisImClis 474.5 a.u. and for the bisImPF 6 , the $\beta_{\mathrm{HRS}}$ is 122.3 a.u. using B3LYP/aug-cc-pVDZ calculation. Therefore, the effect of the anion on the first hyperpolarizabilities values is crucial. This is maybe due to the stronger Coulombic interactions and the weaker van der Waals interactions in the case of bisImCl ion-pairs, whereas in the bis $\mathrm{ImPF}_{6}$ ion-pairs, the charge is more dispersed reported by Raabe et al. [63].This interaction plays an important role to affect the NLO properties. The understanding of these interactions is a challenge in particular for ILs.

Bishopet al.[64] had compared first hyperpolarizabilities $(\beta)$ of ions and showed that the chloride ion $\left(\mathrm{Cl}^{-}\right)$had a strong first hyperpolarizabilities $(\beta)$ compared to the ions studied in their paper.Also, the high hyperpolarizability of bisImCl can be related to the high binding energy between the $\mathrm{Cl}^{-}$and the cation[65]. We can calculate this energy by doing the differences between the total energies of the ion pairs and the separated ions. Zhang et al. [66] showed that the binding energies are depended dramatically on the second hyperpolarizability. On the other hand, Rodriguez etal.[58]showed in their study of the $\beta_{\mathrm{HRS}}$ in ILs using DFT calculations, that the presence of $\mathrm{PF}_{6}^{-}$anion in their series of ILs reduces the $\beta_{\mathrm{HRS}}$ values compared to $\mathrm{BF}_{4}$ and TFSI anions. Similar findings are observed in our present work. The $\beta_{\text {HRS }}$ of each DILs studied in this work is affected by the cation-anion interaction, the cation-anion association result electron charge redistribution, which characterise by a predominant dipolar nature. Indeed, the DR values show the dipole character for these DILs (Table 4 and Figure 11), their values are range from 7.1 to 7.5 using CAM-B3LYP calculations. The HRS value of bisImPF ${ }_{6}$ isobtained at the B3LYP functional is same to the $\mathrm{PF}_{6}$ anion-based imidazolium IL (bmimPF $)_{6}$ [58]. The first hyperpolarizability $\beta$ of these DILs 
is more than five times higher than the urea [67,68] using B3LYP/aug-cc-pVDZ. From theoretical results, it can be stated that these DILs have shown very good NLO activity.

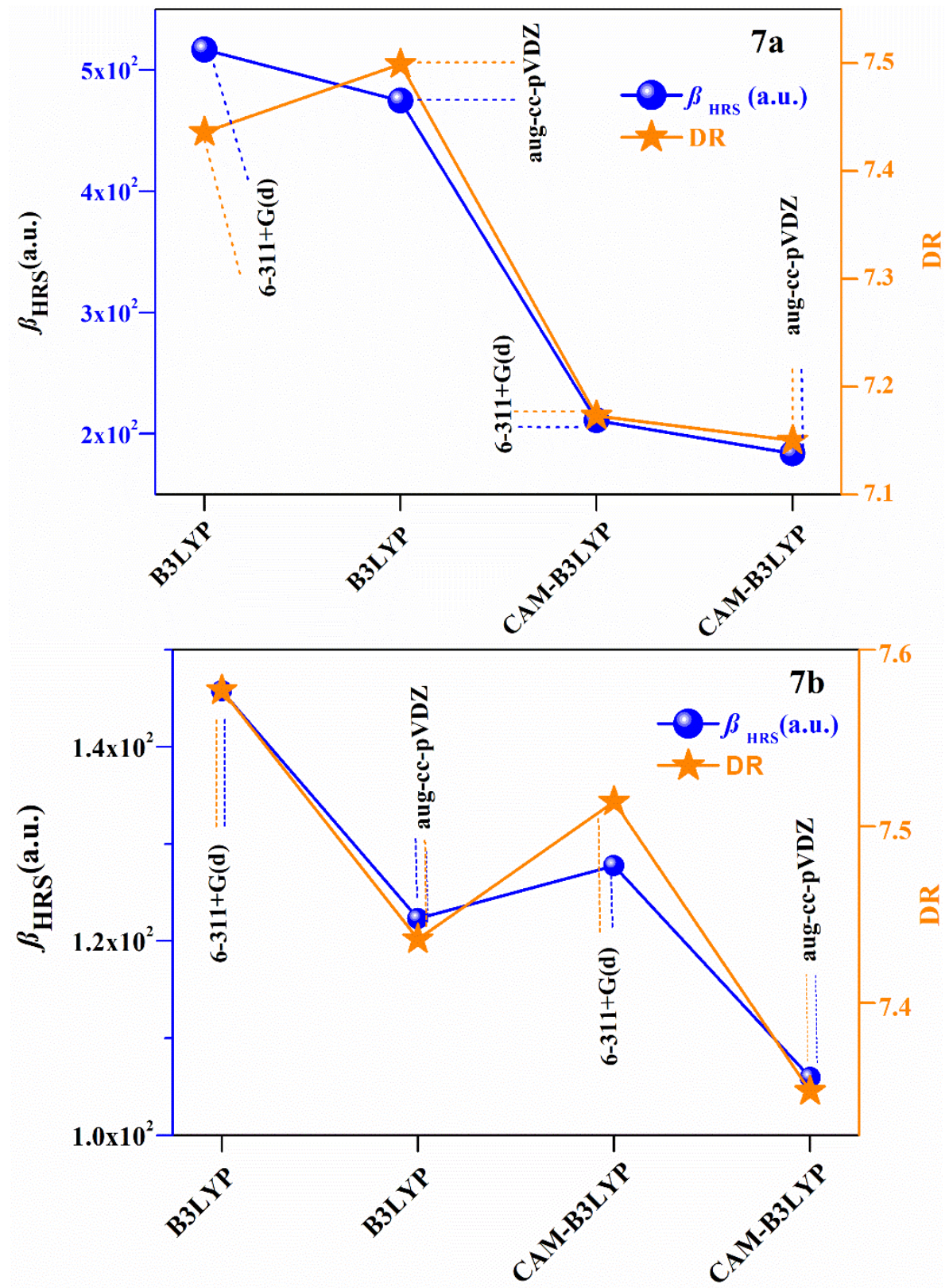

Figure 11. $\beta_{\mathrm{HRS}}$ and $\mathrm{DR}$ for bisImCl (7a) and bisImPF $6(\mathbf{7 b})$ obtained at different levels theory.

\subsection{Frontier molecular orbitals (FMOs)}

The energy difference $(\Delta \varepsilon)$ between the HOMO and LUMO orbitals of these DILs can explain the eventual charge transfer interaction taking place between the cation and anion. The ability to donate an electron is due to the HOMO orbital while the ability to obtain an electron is due to the LUMO. The B3LYP/6-311+G(d) calculations show that $\Delta \varepsilon$ varied from 
$1.96 \mathrm{eV}$ in bisImCl to $3.56 \mathrm{eVinbisImPF}_{6}$ (Table 4 andFigure 12), which implies that the bisImClhas low $\Delta \varepsilon$ values to transfer electrons between the occupied and unoccupied orbitals.

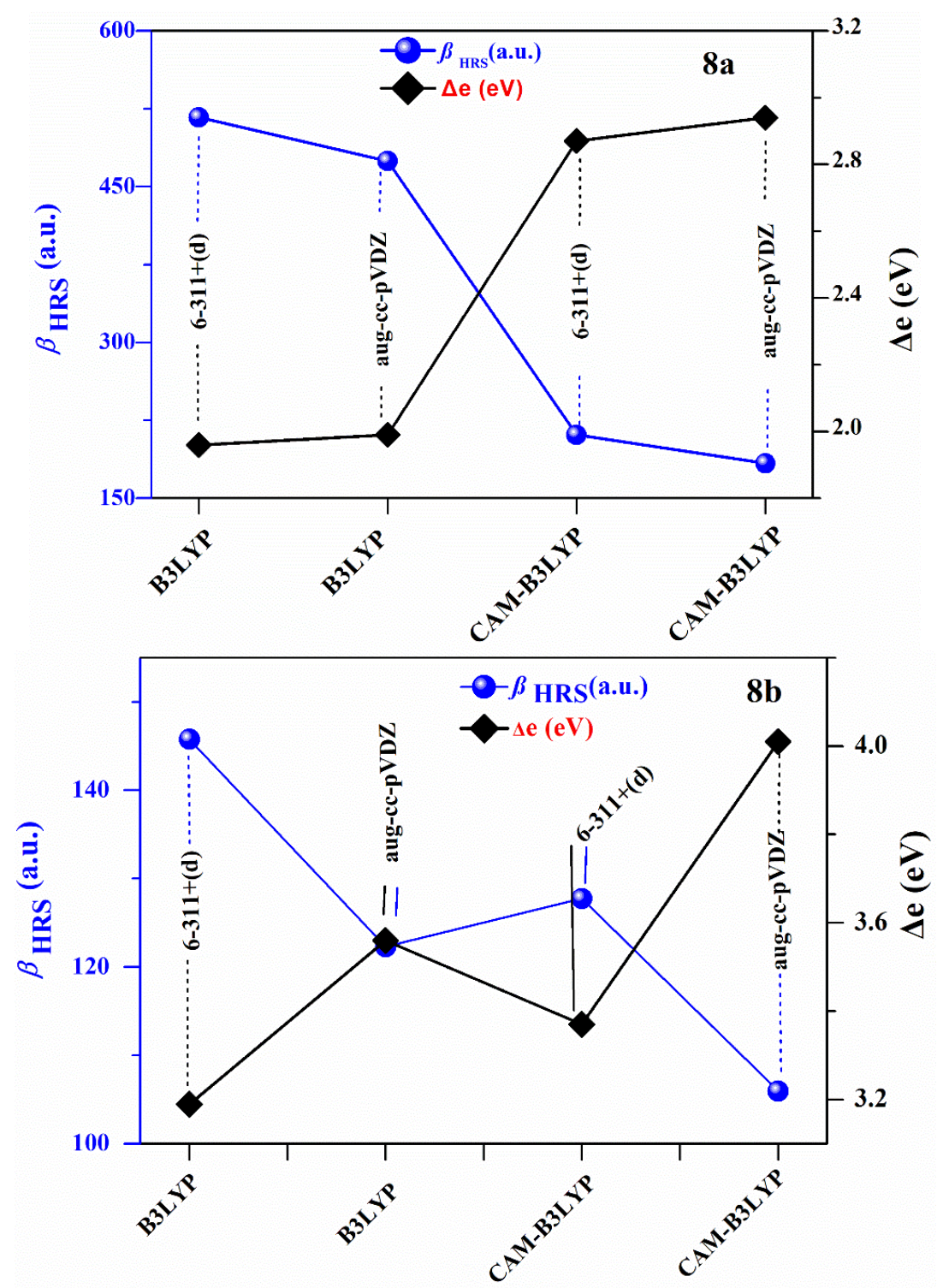

Figure 12.Evolution of the $\beta_{\mathrm{HRS}}$ and $\Delta \varepsilon$ for bisImCl (upper panel) and bisImPF 6 (lower panel) determined at different levels of approximation.

Figure 13 shows that the isodensity surface of the HOMO orbital of these two ILs predicted by the two functionals B3LYP and CAM-B3LYP with the two basis sets 6-311+G(d) and aug-cc-pVDZ are similar. The two DFT levels show that these FMOs are $\pi$-orbitals originated from $\mathrm{p}$ atomic orbitals. The HOMO orbital for the bisImCl is centred in the $\mathrm{Cl}^{-}$anion, while the LUMO orbital is delocalized in the imidazolium ring. This segment shows the positive charge density. In the case of bisImPF 6 , the HOMO orbital is delocalised in the imidazolium ring. Unlike bisImCl DIL, the CAM-B3LYP functional using the two 
basis sets $6-311+\mathrm{G}(\mathrm{d})$ and aug-cc-pVDZ shows that the $\mathrm{HOMO}$ in bis $\mathrm{ImPF}_{6}$ is mainly localized on the phenyl moiety and not in the anion. This fact suggests a weak charge transfer and therefore low hyperpolarizabilities values compared to those obtained for the bisImCl(Table 4). The LUMO shows an electron density delocalized over the cation group. In present work, $\mathrm{HOMO}$ orbital of bisImPF 6 is delocalised in the imidazolium ring segment and not in the $\mathrm{PF}_{6}$. Supported by previously reported work [69]. 

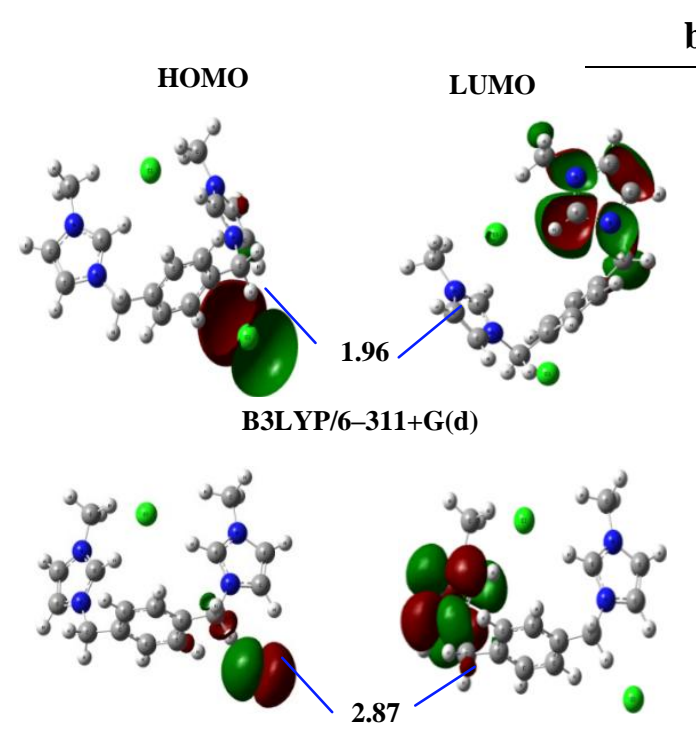

CAM-B3LYP/6-311+G(d)

bisImCl DIL

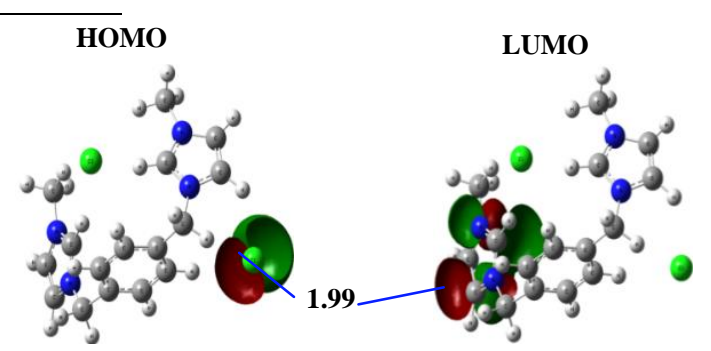

B3LYP/aug-cc-pVDZ

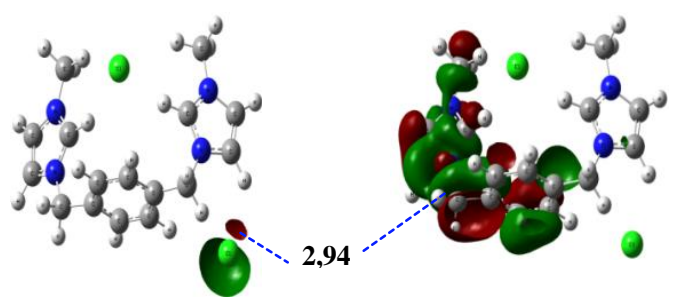

CAM-B3LYP/aug-cc-pVDZ

bisImPF $_{6}$ DIL
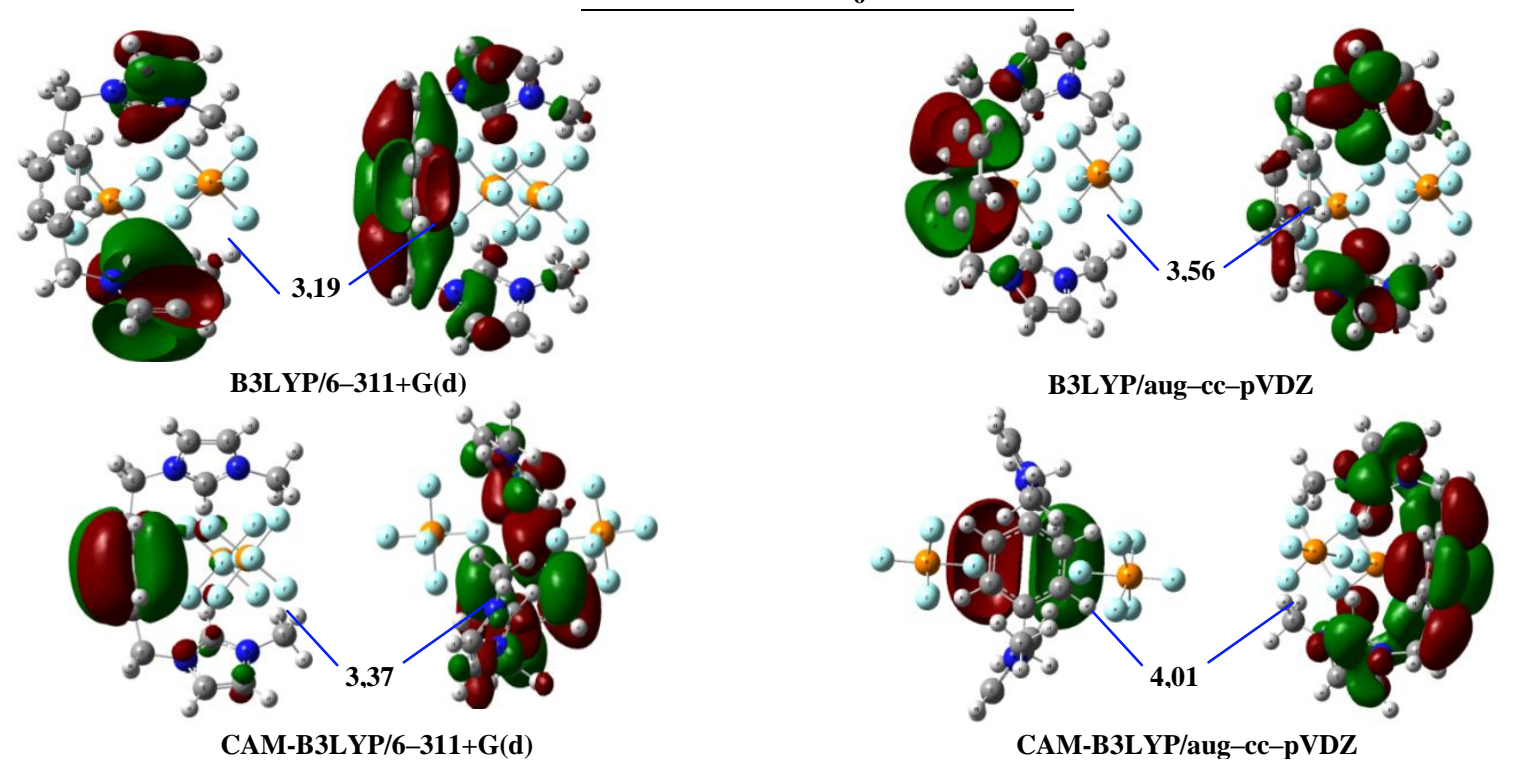

Figure 13.HOMO and LUMO orbitals of bisImCl and bisImPF $\mathrm{DIL}_{6}$ and their $\Delta \varepsilon$ (in eV) estimated by B3LYP and CAM-B3LYP functionals at $6-311+\mathrm{G}(\mathrm{d})$ and aug-cc-pVDZ basis sets.

From these analyses, it can be said that it is reasonable to assume that the imidazolium ring in the case of the bisImPF 6 DIL acts as the main site to donate electrons.

For the bisImClDIL using the B3LYP/6-311+G(d) calculation, the $\Delta \varepsilon$ is $1.96 \mathrm{eV}$ as shown in Figure 12and Table 4. On the other hand, for the bisImPF $\operatorname{DIL}_{6}$, the $\Delta \varepsilon$ value was $3.19 \mathrm{eV}$, which is higher than in bisImCIDIL. The high polarizability and first hyperpolarizability 
results for the bisImClindicate that the bisImCl is easier to polarize, whereas, the bisImPF 6 carries a good resistance for polarization. The high value of gap predicted for bisImPF 6 (3.19 $\mathrm{eV})$ as compared to value obtained for bisImCl $(1.96 \mathrm{eV})$ suggest a high reactivity of bisImCl. Here, the ten $\mathrm{H}$ bonds interactions predicted for BisImPF 6 together with the thirteen new RCPs by AIM calculations justify clearly the low reactivity of this ionic liquid.

An inverse relationship has been found between the gaps and $\beta_{\mathrm{HRS}}$. Indeed, high values of first hyperpolarizabilities $\beta_{\text {HRS }}$ were obtained for low $\Delta \varepsilon$ values. The same observation has been reportedin our recent study on the hyperpolarizabilitiesofthediphenylferrocenylbutene derivatives using theoretical calculations [70]. 


\section{Conclusions}

In the present work, two new di-cationic ionic liquids, namely 3,3'-dimethyl-1,1'-(1,4phenylenedimethylene)-bis(1H-imidazolium) dichloride (bis $\operatorname{ImCl}$ ) and 3,3'-dimethyl-1,1'(1,4-phenylenedimethylene)-bis(1H-imidazolium) bis(hexafluorophosphate) (bisImPF $\left.{ }_{6}\right)$ were successfully synthesized. Both ionic liquids have been characterized by FT-Raman and ${ }^{1} \mathrm{H}$ - and ${ }^{13} \mathrm{C}-\mathrm{NMR}$ spectroscopies. Monodentatecordinations of $\mathrm{Cl}$ atoms with $\mathrm{C}-\mathrm{H}$ bonds of imidazolium groups were predicted for BisImCl by B3LYP/6-311++G** calculations while in $\mathrm{BisImPF}_{6}$ only a PF6 group is in monodentate coordination with the $\mathrm{C}-\mathrm{H}$ bond corresponding to cation.

The thermal behavior confirmed that bisImCl and bisImPF 6 have shown good thermal stability. The p-xylyl group plays important role on intermolecular interaction among cationanion and cation-cation pair. The decomposition temperature of bis $\mathrm{ImCl}$ is lower than

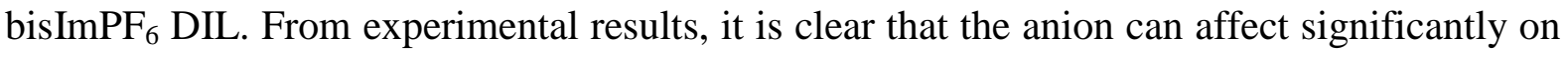
decomposition of these DILs. From Raman vibrational spectra of these DILs, the imidazolium ring vibration modes $\left(\mathrm{C}_{4}-\mathrm{H} / \mathrm{C}_{5}-\mathrm{Hand} \mathrm{C}_{2}-\mathrm{H}\right)$ are significantly altered depending of nature of anion. The chemical shift of $\mathrm{C}_{2}-\mathrm{H}$ proton is more downfield for bis ImCl compared to bisImPF 6 DIL. The chemical shifts were strongly influenced in the case of chloride anion and their local environment. Further, higher polarizability $(\alpha)$ and the static first hyperpolarizabilities $(\beta)$ of these ILs are observed from DFT calculation using different functionals to understand origin of NLO properties. BisImCl has shown higher polarizability $(\alpha)$ and the static first hyperpolarizabilities $(\beta)$ compared to bisImPF $F_{6}$. The $\beta$ values for bisImPF $_{6}$ using $\mathrm{B} 3 \mathrm{LYP} / \mathrm{aug}-\mathrm{cc}-\mathrm{pVDZ}$ level are more than 5 times of that of urea and bisImCl. However,depolarization ratios (DR) remain constant for these DILs.It is also observed an inversed correlation between the predicted $\beta$ value and the HOMO-LUMO energy difference $(\Delta \varepsilon)$ from two state models. The AIM calculations suggest a high stability of bisImPF 6 , as compared to bisImCl DIL which is supported by the high gap value predicted for this ionic liquid. Hence, a higher reactivity is revealed for bisImCl DIL.

The complete assignments for cation, bisImCl and bisImPF are here reported together with a set of harmonic scaled force constants calculated for cation and bisImCl. 


\section{Acknowledgments}

This work was supported by the WBI-COP22 Morocco project and UM5R as well as grants from CIUNT Project No 26/D608 (Consejo de Investigaciones, Universidad Nacional de Tucumán). The authors would like to thank Prof. Tom Sundius for his permission to use MOLVIB.

ORCID Haddad Boumediene 1 https://orcid.org/0000-0001-9198-9528

ORCIDHadjiDjebar ${ }^{\mathbb{Q} h t t p}$ ://orcid.org/0000-0003-3058-0627

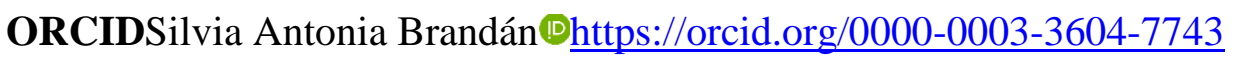

ORCIDSumitKumarPanjahttps://orcid.org/0000-0001-5658-0452

ORCIDAnnalisaPaolone (Dhttps://orcid.org/0000-0002-4839-7815

ORCIDMokhtarDrai(Dhttps://orcid.org/0000-0001-5421-5240

ORCID Didier Villemin 1 https://orcid.org/0000-0002-6266-3817

ORCIDSergeBresson $\mathbb{D h}_{\text {htps://orcid.org/0000-0003-0932-0468 }}$

ORCID Mustapha Rahmouni@ $\underline{\text { https://orcid.org/0000-0003-1552-7465 }}$

\section{Compliance with ethical standards}

Conflict of interest : The authors declare that they have no conflicts of interest 


\section{References}

1. R.D. Rogers,K.R. Seddon, Ionic liquids--solvents of the future?, Science, 302(5646), (2003) 792-793.

2. E. Sundstrom,J. Yaegashi,J.Yan, F. Masson, G. Papa, A. Rodriguez, , ... J. Gladde,. Demonstrating a separation-free process coupling ionic liquid pretreatment, saccharification, and fermentation with Rhodosporidiumtoruloides to produce advanced biofuels, Green Chem. 20 (2018) 2870-2879.

3. D.G. Seo, H.C. Moon, Mechanically robust, highly ionic conductive gels based on random copolymers for bending durable electrochemical devices,Adv. Funct. Mater. 28 (2018) 1706948.

4. A.A. Elgharbawy, F.A. Riyadi,M.Z. Alam, M. Moniruzzaman, Ionic liquids as a potential solvent for lipase-catalysed reactions: a review,J. Mol. Liq. 251 (2018) 150-166.

5. T. Welton, Ionic liquids: a brief history. Biophysical reviews, 10 (2018) 691-706.

6. K. Oster, J. Jacquemin, C. Hardacre, A.P.C. Ribeiro,A. Elsinawi, Further development of the predictive models for physical properties of pure ionic liquids: Thermal conductivity and heat capacity,J. Chem. Thermodyn., 118 (2018) 1-15.

7. M.F. Ali, J. Gan, X. Chen, G. Yu, Y. Zhang, M. Ellahi, A.A. Abdeltawab, Hydrodynamic modeling of ionic liquids and conventional amine solvents in bubble column, Chem. Eng. Res. Des. 129 (2018) 356-375.

8. J.L. Shamshina, O. Zavgorodnya, P. Berton, P.K. Chhotaray, H. Choudhary, R.D. Rogers, Ionic Liquid Platform for Spinning Composite Chitin-Poly (lactic acid) Fibers,ACS Sustain. Chem. Eng. 6 (2018) 10241-10251.

9. M.B. Vazquez-Santos, P. Tartaj, E. Morales, J.M. Amarilla, $\mathrm{TiO}_{2}$ Nanostructures as Anode Materials for Li/Na-Ion Batteries,Chem. Rec. 18 (2018) 1178-1191.

10. B. Haddad, D. Villemin, E.H. Belarbi, N. Bar, M. Rahmouni, New dicationicpiperidiniumhexafluorophosphate ILs, synthesis, characterization and dielectric measurements,Arab. J. Chem.7 (2014) 781-787.

11. B. Haddad, T. Moumene, D. Villemin, J.F. Lohier, E.H Belarbi, Bis-methyl imidazoliummethylidenebis (trifluoromethanesulfonyl) imide, crystal structure, thermal and dielectric studies,Bull. Mater. Sci. 39 (2016) 797-801.

12. D.K. Kaczmarek, K. Czerniak, T. Klejdysz, Dicationic ionic liquids as new feeding deterrents, Chem. Pap. 72 (2018) 2457-2466.

13. R.A. Patil, M. Talebi, A. Berthod, D.W. Armstrong, Dicationic ionic liquid thermal decomposition pathways,Anal. Bioanal. Chem.410 (2018) 4645-4655.

14. E. Gurung, D. Meng, L. Xue,G. Tamas, R.M. Lynden-Bell, E.L. Quitevis, Optical Kerr effect spectroscopy of CS2 in monocationic and dicationic ionic liquids: insights into the intermolecular interactions in ionic liquids,Phys. Chem. Chem. Phys. 20 (2018) 2655826569.

15. J.C. Águila, M. Trejo-Durán, Theoretical study of the second-order nonlinear optical properties of ionic liquids,J. Mol. Liq. 269 (2018) 833-838.

16. J.E. Castellanos-Águila, M.A. Olea-Amezcua, H. Hernández-Cocoletzi, M. Trejo-Durán, Tuning the nonlinear optical properties of the [alkyl-Py] $+\left[\mathrm{NO}_{3}\right]-$ and [alkyl$\mathrm{MIM}]+\left[\mathrm{NO}_{3}\right]-$ ionic liquids,J. Mol. Liq. 285 (2019) 803-810.

17. I. Severiano-Carrillo, E. Alvarado-Méndez, K.A. Barrera-Rivera, M.A. Vázquez, M. Ortiz-Gutierrez, M. Trejo-Durán, Studies of optical nonlinear properties of asymmetric ionic liquids,Opt. Mater. 84 (2018) 166-171.

18. M. Trejo-Durán, E. Alvarado-Méndez, K.A. Barrera-Rivera, V.M. Castaño, Nonlinear optical phenomena in Bi-ionic Liquids, Optik, 130 (2017) 895-899.

19. S. Anandhi, K.M. Rahulan, T.S. Shyju, Hyperpolarizability and two photon observation of imidazoliumpicrate, Optik, 125 (2014) 7132-7135. 
20. D.J. Williams, Nonlinear optical properties of organic and polymeric materials. In ACS symposium series 233. ACS, (1983).

21. R.F. Souza, M.A.R.C. Alencar, M.R. Meneghetti, J. Dupont, J.M. Hickmann, Nonlocal optical nonlinearity of ionic liquids,J. Phys. Condens. Matter. 20 (2008) 155102.

22. M.S. Kodikara, R. Stranger, M.G. Humphrey, Computational studies of the nonlinear optical properties of organometallic complexes, Coord. Chem. Rev. 375 (2018) 389-409.

23. G. Marino, P. Segovia, A.V. Krasavin, P. Ginzburg, N. Olivier, G.A. Wurtz, A.V. Zayats, Second-harmonic generation from hyperbolic plasmonicnanorodmetamaterialslab,Laser Photonics Rev. 12 (2018) 1700189.

24. O. Ostroverkhova, W.E. Moerner, Organic photorefractives: mechanisms, materials, and applications,Chem. Rev. 104 (2004) 3267-3314.

25. C.E. Song, Enantioselective chemo-and bio-catalysis in ionic liquids,Chem. Comm.(2004) 1033-1043.

26. S. Bugaychuk, G. Klimusheva, Y. Garbovskiy, T. Mirnaya, A. Ischenko, Nonlinear optical properties of composites based on conductive metal-alkanoate liquid crystals,Opto-Electron Rev. 14 (2006) 275-279.

27. B. Haddad, A. Paolone, M. Drai, M. Boumediene, D. Villemin, E.H. Belarbi,... O. Abbas, Para-xylyl linked bis-imidazolium ionic liquids: A study of the conformers of the cation and of the anion-cation hydrogen bonding,J. Mol. Struct., 1175 (2019) 175-184.

28. R. Bader, AIMPAC: a suite of programs for the theory of atoms in molecules, Hamilton, Canada (contact http://www. chemistry. mcmaster. ca/aimpac) Search PubMed; RFW Bader, Atoms in Molecules: A Quantum Theory. ISBN: 0198558651, (1990).

29. F.B. König, J. Schönbohm, D. Bayles, AIM2000-a program to analyze and visualize atoms in molecules,J. Comput. Chem. 22 (2001) 545-559.

30. P. Pulay, G.Fogarasi, G. Pongor, J.E. Boggs, A. Vargha, Combination of theoretical ab initio and experimental information to obtain reliable harmonic force constants. Scaled quantum mechanical (QM) force fields for glyoxal, acrolein, butadiene, formaldehyde, and ethylene,J. Am. Chem. Soc. 105 (1983) 7037-7047.

31. G. Rauhut, P. Pulay, Transferable scaling factors for density functional derived vibrational force fields,J. Phys. Chem. 99 (1995) 3093-3100.

32. A.T. Sundius, Scaling of ab initio force fields by MOLVIB,Vib. Spectrosc. 29 (2002) 8995.

33. M.J. Frisch, G.W. Trucks, H.B. Schlegel, G.E. Scuseria, M.A. Robb, J.R. Cheeseman,... H. Nakatsuji, Gaussian09, revisions D. 01 and B. 01; Gaussian, Inc. Wallingford, CT, (2010).

34. R. Dennington, T. Keith, J. Millam, Semichem Inc., Shawnee Mission Ks. GaussView, Version, 5. (2009).

35. A.D. Becke, Density-functional exchange-energy approximation with correct asymptotic behaviour,Phy. Rev. A, 38 (1988) 3098.

36. P. Ugliengo, Moldraw Program. University of Torino, DipartimentoChimica IFM, Torino, Italy, (1998).

37. H. Boumediene, S.A. Brandán, A.M. Amin, A. Paolone, D. Villemin, S. Bresson, Bidentatecation-anion coordination in the ionic liquid 1-ethyl-3-methylimidazolium hexafluorophosphate supported by vibrational spectra and NBO, AIM and SQMFF calculations,J. Mol. Struct. 1212 (2020) 128104.

38. K. Noack, P.S. Schulz, N. Paape, J. Kiefer, P. Wasserscheid, A. Leipertz, The role of the C2 position in interionic interactions of imidazolium based ionic liquids: a vibrational and NMR spectroscopic study,Phys. Chem. Chem. Phys. 12 (2010) 14153-14161. 
39. A.D. Headley, N.M. Jackson, The effect of the anion on the chemical shifts of the aromatic hydrogen atoms of liquid 1-butyl-3-methylimidazolium salts,J. Phys. Org. 15 (2002) 52-55.

40. J. Rigby, E.I. Izgorodina, Assessment of atomic partial charge schemes for polarisation and charge transfer effects in ionic liquids, Phys. Chem. Chem. Phys. 15 (2013) 16321646.

41. R.K. Blundell, P. Licence, Tuning cation-anion interactions in ionic liquids by changing the conformational flexibility of the cation,Chem. Commun. 50 (2014) 12080-12083.

42. P.A. Hunt, I.R. Gould, B. Kirchner, The structure of imidazolium-based ionic liquids: Insights from ion-pair interactions, Aust. J. Chem. 60 (2007) 9-14.

43. S. Tsuzuki, H. Tokuda, M. Mikami, Theoretical analysis of the hydrogen bond of imidazolium C 2-H with anions,Phys. Chem. 9 (2007) 4780-4784.

44. T. Cremer, C. Kolbeck, K.R. Lovelock, N. Paape, R. Wölfel, P.S. Schulz,... F. Maier,Towards a Molecular Understanding of Cation-Anion Interactions-Probing the Electronic Structure of Imidazolium Ionic Liquids by NMR Spectroscopy, X-ray Photoelectron Spectroscopy and Theoretical Calculations, Chem. Eur. J. 16 (2010) 90189033.

45. H. Ibrahim, N.A. Koorbanally, D. Ramjugernath, M.D. Bala, V.O. Nyamori, Synthesis and characterization of imidazolium salts bearing fluorinated anions,Z. Anorg. Allg. Chem. 638 (2012) 2304-2309.

46. B. Haddad, D. Mokhtar, M. Goussem, E.H. Belarbi, D. Villemin, S. Bresson, ... J. Kiefer, Influence of methyl and propyl groups on the vibrational spectra of two imidazolium ionic liquids and their non-ionic precursors,J. Mol. Struct. 1134 (2017) 582-590.

47. B. Haddad, A. Paolone, D. Villemin, J.F. Lohier, M. Drai, S. Bresson,... E.H. Belarbi, para-Xylyl bis-1-methylimidazolium bis (trifluoromethanesulfonyl) imide: Synthesis, crystal structure, thermal stability, vibrational studies,J. Mol. Liq. 260 (2018) 391-402.

48. B. Haddad, A. Paolone, D. Villemin, M. Taqiyeddine, E.H. Belarbi, S. Bresson, ... J. Kiefer, Synthesis, conductivity, and vibrational spectroscopy of tetraphenylphosphonium bis (trifluoromethanesulfonyl) imide,J. Mol. Struct.1146 (2017) 203-212.

49. M. Boumediene, B. Haddad, A. Paolone, M. Drai, D. Villemin, M. Rahmouni,... O. Abbas, Synthesis, thermal stability, vibrational spectra and conformational studies of novel dicationic meta-xylyl linked bis-1-methylimidazolium ionic liquids,J. Mol. Struct. 1186 (2019) 68-79.

50. A.M. Moschovi, S. Ntais, V. Dracopoulos, V. Nikolakis, Vibrational spectroscopic study of the protic ionic liquid 1-H-3-methylimidazolium bis (trifluoromethanesulfonyl) imide,Vib. Spectrosc. 63(2012) 350-359.

51. V.H. Paschoal, L.F. Faria, M.C. Ribeiro, Vibrational Spectroscopy of Ionic Liquids, Chem. Rev. 117 (2017) 7053-7112.

52. T. Endo, H. Murata, M. Imanari, N. Mizushima, H. Seki, K. Nishikawa, NMR Study of Cation Dynamics in Three Crystalline States of 1-Butyl-3-methylimidazolium Hexafluorophosphate Exhibiting Crystal Polymorphism, J. Phys. Chem. B, 116 (2012) 3780-3788.

53. E.R. Talaty, S. Raja, V.J. Storhaug, A. Dölle, W.R. Carper, Raman and infrared spectra and ab initio calculations of C2-4MIM imidazolium hexafluorophosphate ionic liquids,J. Phys. Chem. B, 108 (2004) 13177-13184.

54. B. Haddad, J. Kiefer, H. Brahim, E.-h. Belarbi, D. Villemin, S. Bresson, O. Abbas, M. Rahmouni, A. Paolone, O. Palumbo, Effects of C(2) Methylation on Thermal Behavior and Interionic Interactions in Imidazolium-Based Ionic Liquids with Highly Symmetric Anions, Appl. Sci. 8 (7) (2018) 1043. 
55. T. Moumene, E.H. Belarbi, B. Haddad, D. Villemin, O. Abbas, B. Khelifa, S. Bresson, Vibrational Spectroscopic Study of Imidazolium Dicationic Ionic Liquids: Effect of Cation Alkyl Chain Length, J. Appl. Spectrosc. 83 (2) (2016)165-171.

56. F. Castet, E. Bogdan, A. Plaquet, L. Ducasse, B. Champagne, V. Rodriguez, Reference molecules for nonlinear optics: A joint experimental and theoretical investigation,J. Chem. Phys. 136 (2012) 024506.

57. R. Bersohn, Y.H. Pao, H.L. Frisch, Double-quantum light scattering by molecules,J. Chem. Phys. 45 (1966) 3184-3198.

58. V. Rodriguez, J. Grondin, F. Adamietz, Y. Danten, Local structure in ionic liquids investigated by hyper-Rayleigh scattering,J Phys. Chem. B, 114 (2010) 15057-15065.

59. D. Hadji, A. Rahmouni, Theoretical study of nonlinear optical properties of some azoic dyes, Mediterr. J. Chem., 4 (2015) 185-192.

60. D. Hadji, A. Rahmouni, Molecular structure, linear and nonlinear optical properties of some cyclic phosphazenes: A theoretical investigation,J. Mol. Struct. 1106 (2016) 343351.

61. D. Hadji, H. Brahim, Structural, optical and nonlinear optical properties and TD-DFT analysis of heteroleptic bis-cyclometalated iridium (III) complex containing 2phenylpyridine and picolinate ligands, Theor. Chem. Acc. 137 (2018) 180.

62. M. Shkir, S. AlFaify, H. Abbas, S. Muhammad, First principal studies of spectroscopic (IR and Raman, UV-visible), molecular structure, linear and nonlinear optical properties of 1-arginine p-nitrobenzoate monohydrate (LANB): a new non-centrosymmetric material. Spectrochimica Acta Part A, 147 (2015) 84-92.

63. G. Raabe, J. Köhler, Thermodynamical and structural properties of imidazolium based ionic liquids from molecular simulation,J. Chem. Phys. 128 (2008) 154509

64. D.M. Bishop, J. Pipin, Dipole, quadrupole, octupole, and dipole-octupole polarizabilities at real and imaginary frequencies for $\mathrm{H}, \mathrm{HE}$, and $\mathrm{H}_{2}$ and the dispersion-energy coefficients for interactions between them,Int. J. Quantum Chem. 45 (1993) 349-361.

65. I. Khan, M. Taha, P. Ribeiro-Claro, S.P. Pinho, J.A. Coutinho, Effect of the cation on the interactions between alkyl methyl imidazolium chloride ionic liquids and water,J. Chem. Phys. B, 118 (2014) 10503-10514.

66. Z.H. Zhang, J.S. Li, J. Tang, L.L. Yang, K.X. Guo, J.H. Yuan, Binding energy and the third-order nonlinear optical susceptibility of an exciton in GaAs/AlGaAs core/shell spherical quantum dot,J. Opt. 47 (2018) 445-455.

67. D. Sakthi, M. Prakasam, A. Prakasam, S. Sivakumar, P.M. Anbarasan, A Complete DFT, TD-DFT and Non-Linear Optical Property Study on 6-Amino-2-Methylpyridine-3Carbonitrile, Computational Chemistry, 5 (2017) 129.

68. I. Ledoux, J. Zyss, Influence of the molecular environment in solution measurements of the second-order optical susceptibility for urea and derivatives, Chem. Phys. 73 (1982) 203-213.

69. A. Yousefi, S. Javadian, N. Dalir, J. Kakemam, J. Akbari, Imidazolium-based ionic liquids as modulators of corrosion inhibition of SDS on mild steel in hydrochloric acid solutions: experimental and theoretical studies, RSC Advances, 5 (2015) 11697-11713.

70. D. Hadji, A. Rahmouni, D. Hammoutène, O. Zekri, First theoretical study of linear and nonlinear optical properties of diphenyl ferrocenyl butene derivatives, J.Mol. Liq. 286 (2019) 110939. 
